\title{
Analysis of Aliphatic Waxes Associated with Root Periderm or Exodermis from Eleven Plant Species
}

Dylan K. Kosma ${ }^{\star a}$, Adam Rice, Mike Pollard

Department of Plant Biology, Michigan State University, East Lansing, Michigan, USA

${ }^{*}$ Corresponding Author

Address: Department of Plant Biology, Michigan State University, 612 Wilson Rd

Room 366, East Lansing, Michigan, 48824, USA

Telephone: +1 517 355-5237

Fax: +1517 353-1926

E-mail: dkosma@msu.edu

${ }^{a}$ Current Address: Department of Biochemistry and Molecular Biology, University of Nevada, Mail Stop 0330, Reno, Nevada, 89557, USA

Email:dkosma@unr.edu

The authors declare no conflict of interest. 


\section{Abstract}

Aliphatic waxes can be found in association with suberized tissues, including roots. Non-polar lipids were isolated by rapid solvent extraction of mature regions of intact roots from eleven angiosperms, including both monocots and dicots. The majority of roots analyzed were taproots or tuberous taproots that had undergone secondary growth and thus were covered by a suberized periderm. The exceptions therein were maize (Zea mays L.) and rice (Oryza sativa L.), which present a suberized exodermis. The analysis herein focused on aliphatic waxes, with particular emphasis on alkyl hydroxycinnamates (AHCs). AHCs were widely distributed, absent from only one species, were found in both aerial and subterranean portions of tuberous taproots, and were associated with the fibrous roots of both maize and rice. Most species also contained monoacylglycerols, fatty alcohols and/or free fatty acids. Carrot (Daucus carrota L.) was the outlier, containing only free fatty acids, sterols, and polyacetylenes as identified components. Sterols were the only ubiquitous component across all roots analyzed. Monoacylglycerols of $\omega$-hydroxy fatty acids were present in maize and rice root waxes. For species within the Brassiceae, wax compositions varied between subspecies or varieties and between aerial and subterranean portions of taproots. In addition, reduced forms of photo-oxidation products of $\omega$ hydroxy oleate and its corresponding dicarboxylic acid (10,18-dihydroxy-octadec8-enoate, 9,18-dihydroxy-octadec-10-enoate and 9-hydroxyoctadec-10-ene-1,18dioate) were identified as naturally occurring suberin monomers in rutabaga (Brassica napus subsp. rapifera Metzg.) periderm tissues. 
Key Words: Alkyl hydroxycinnamate; suberin; root wax; suberin-associated waxes; periderm; exodermis; photo-oxidation 


\section{Introduction}

Compositions of taproot surface lipids ("root waxes") were first reported by Espelie et al. (1980). The methodology employed allowed identification and quantification of free fatty acids, fatty alcohols, and alkanes and their mid-chain keto or hydroxy derivatives. Later studies in Arabidopsis provided evidence for additional root wax classes, namely alkyl hydroxycinnamates (AHCs), sterols and monoacylglycerols (MAGs) (Li et al., 2007a; Molina et al., 2009). Plant AHCs are typically ferulic, coumaric, or caffeic acids esterified to saturated fatty alcohols with carbon chain lengths ranging from $\mathrm{C} 16$ to $\mathrm{C} 32$. They have been reported to occur in several higher plant species (García-Argáez et al., 1999; Gutiérrez Suárez et al., 2004; Schmutz et al., 1994; Yunoki et al., 2004). Typically they are found associated with suberized tissues, like the periderm of roots or stems (tree bark) (Bernards and Lewis, 1992; Freire et al., 2007; Kawanishi et al., 1990; Schreiber et al., 2005; Sun et al., 2006) and green cotton fibers (Schmutz et al., 1994). There is one report of alkyl coumarates associated with cutinized tissues (Santos et al., 2007).

Recent literature has described the identification of several enzymes required for root wax biosynthesis. These include enzymes also involved in suberin polymer synthesis. A glycerol-3-phosphate sn-2 acyltransferase (GPAT5; At3g11430) catalyzes the synthesis of lysophosphatidic acid, a precursor for both aliphatic suberin and root-wax associated MAGs (Beisson et al., 2007; Li et al., 2007a; Yang et al., 2010; Yang et al., 2012). A specific HXXXD-motif/BAHD acyltransferase is responsible for the synthesis of ferulate esters in both the 
suberin polymer and periderm waxes of potato tubers (Serra et al., 2010). Whereas alkyl ferulates are the sole class of AHCs of potato periderm waxes, Arabidopsis taproot periderm waxes contain alkyl coumarates, alkyl caffeates, and small amounts of alkyl ferulates. A related HXXXD-motif/BAHD acyltransferase (At5g63560) in Arabidopsis was shown to be specific for the synthesis of alkyl caffeates in the periderm of taproots (Kosma et al., 2012). Three fatty acyl-CoA reductases (AtFAR1/4/5) are required for AHC synthesis, presumably by providing fatty alcohols as acyl acceptors (Domergue et al., 2010; Vishwanath et al., 2013).

Since several suberin biosynthetic enzymes are required for root wax synthesis (Kosma et al., 2012; Li et al., 2007a; Serra et al., 2010), it can be surmised that at least some of these waxes are synthesized in suberizing tissues (e.g. the periderm). However, any temporal overlap between suberin and wax synthesis has yet to be directly demonstrated. Root wax extraction kinetics with Arabidopsis have shown that alkanes are immediately extracted $(<10 \mathrm{~s})$, whereas very-long-chain free fatty acids, primary alcohols, and AHCs take about $120 \mathrm{~s}$ for complete extraction (Li et al., 2007a). Alkane extraction is thus suggestive of a superficial localization as would be found for cuticular waxes, whereas the other root wax components could have a deeper localization. Whether this implies an intracellular, extracellular or even a suberin lamellaeassociated localization remains unclear. Periderm cells actively synthesizing suberin will have the molecular machinery to transport lipids to the cell wall, so it is reasonable to propose an extracellular site for the deposition of root waxes. 
Localization is likely related to function. Suberization as a wound response is well established and studied in potato tubers (Bernards and Lewis, 1992; Boher et al., 2013; Schreiber et al., 2005). Mature regions of roots that undergo secondary growth are covered by a suberized periderm that is considered a protective barrier against the environment. These root surfaces represent an important interface for interactions between plants and their environment in the rhizosphere. Collectively or individually, the root wax compounds may contribute to generic barrier- or permeability-associated properties of suberized tissues but exact biological functions remain uncertain.

In this study, eleven plant species were analyzed for their root wax compositions. A particular emphasis has been the occurrence and diversity of AHCs. These are widely distributed throughout the higher plant kingdom. We Aerial and subterranean portions of tuberous taproots were analyzed individually and it was found that wax and suberin content and composition vary substantially with position. For two species from the Brassiceae (rutabaga and rapeseed, $B$. napus; radish and daikon, Raphanus sativus L.), pairs of subspecies or varieties showed significant variability in composition. Also identified were reduced forms of photo-oxidation products of oleate-derived suberin monomers as native components of periderm suberin of rutabaga, with a distribution along the root axis consistent with degree of exposure to light.

\section{Results and Discussion}


In the first section, it wax confirmed that the root surface tissues are suberized. As some taproots have substantial above ground portions, analysis of the distribution of both root waxes and suberin monomers with position along the vertical axis in rutabaga was carried out. During this analysis novel suberin monomers were identified, which are reported in section 2.3. Section 2.4 provides a description of lipid root classes across all the species analyzed, with section 2.5 providing details for AHCs. Finally, in section 2.6, information is provided on intraspecific variability. In discussing the details of composition below, a complete data set is available in Supplemental File [1] when data are not explicitly presented in the Tables or Figures.

\subsection{Plant Species Analyzed and Confirmation of Suberization of their Root Periderm or Exodermis}

Plant species utilized in this study (Fig S1) were selected from 6 plant families and represent species of agricultural and genomic interest differing in root morphology (Fig S2; tuberous versus non-tuberous, fibrous versus taproot, etc.), abiotic stress tolerance and type of suberized tissue (periderm versus exodermis). Maize and rice were selected because they represent species with roots that do not undergo secondary growth (including periderm formation) but do possess a suberized exodermis (Hose et al., 2001; Schreiber et al., 2005b). Nine plant species described in this study were grown in a greenhouse, two [Arabidopsis and salt cress (Eutrema salsugineum (Pall.) Al-Shehbaz \& Warwick ecotype Yukon)] in a growth chamber, with the intent of minimizing any stress 
responses, although at this time it is not known how growth conditions and pathogens may affect root wax compositions. Only Arabidopsis and salt cress were not commercial cultivars. It is unclear how domestication of the 9 other species may affect compositions.

In parallel with chemical analyses, it was important to ascertain if each of the species possessed a suberized periderm, or exodermis in the case of maize and rice. Root periderm sections were analyzed via Transmission Electron Microscopy (TEM). Substantial variability was evident in the number and thickness of light and dark bands, termed lamella, across species and between aerial versus subterranean portions. However, the TEM analyses were aimed at confirming suberization in the form of lamellae rather than extensively documenting inherent variability. Sections were taken from different areas of the root and from 2-3 biological replicates for each species. The micrographs presented in figures 1 and 2 are representative of what was observed in these samples. The micrographs clearly demonstrated that all species possessed the lamellar structures typical of suberized tissues and that both above- (aerial) and below- (subterranean) ground taproot portions possessed suberin lamellae (Figs. 1, 2).

\subsection{Heterogeneity of Suberin and Root Wax Compositions along the Vertical Axis of Taproots}

Some plant species develop tuberous taproots with substantial simultaneous growth above and below the soil-line; for example, rutabaga, radish (R. sativus L. var. sativus cv. French Breakfast) and daikon (R. sativus L. var. niger J. Kern. cv. Mino Early). Aerial portions are exposed to drier environments 
and more sunlight. Subterranean portions grow and develop in darker, more humid environments with greater exposure to rhizosphere-inhabiting microorganisms. Given these contrasting environments, it was opted to determine if wax and suberin compositions and periderm cell wall ultrastructure differed substantially between aerial and subterranean regions of the taproot periderm. Rutabaga was selected for these more comprehensive analyses.

TEM analysis demonstrated the presence of lamellae in aerial, interfacial and subterranean portions of the rutabaga periderm (Fig. 2). Although subterranean lamellae appear more disorganized than aerial lamellae, it is difficult to make precise interpretations as sectioning technique can influence the appearance of lamellae. Nonetheless, suberin lamellae were present in both the aerial and subterranean periderm of rutabaga with approximately 3 cell files of suberized periderm in each respective portion of the tuber.

In presenting tabulations of root wax composition, two general points should be made explicit. First, wax loads expressed on a mass per unit surface area basis do not imply a uniform distribution across the root surface layers. Second, different root wax classes may have distinctly different transverse or lateral localizations within the extracted surface tissue layers. Analysis of the waxes extracted by rapid immersion of intact rutabaga taproots demonstrated a wax composition similar to that reported for Arabidopsis (Kosma et al., 2012; Li et al., 2007a). However, the total wax load (expressed on a unit surface area basis) of the aerial portion of the rutabaga tuber $\left(5.7 \pm 1 \mu \mathrm{g} \mathrm{cm}^{-2}, n=4\right)$ was substantially greater than either the subterranean portion $\left(1.2 \pm 0.1 \mu \mathrm{g} \mathrm{cm}^{-2}, n=\right.$ 
4) or the interface between the aerial and subterranean portions $\left(1.7 \pm 0.1 \mu \mathrm{g} \mathrm{cm}^{-}\right.$

$\left.{ }^{2}, n=4\right)$ (Fig. 3a; Table 1). Moreover, marked differences in wax composition were evident between aerial and subterranean regions of rutabaga periderm (Fig. 3b). On a mass per unit area basis, aerial portions were substantially enriched in MAGs, alkyl coumarates, primary alcohols and free fatty acids (FFAs). Notably, sterols were present in substantial amounts in both aerial and subterranean periderm portions. Aerial and subterranean portions contained roughly equal amounts of sterols. On a mol \% basis, subterranean portions were enriched in alkyl caffeate esters, sterols such as $\beta$-sitosterol (C29:1 sterol) and docosanol (C22 1-alcohol).

Rutabaga produces a roughly 80 -fold higher load per unit of surface area of alkanes, and their mid-chain keto/hydroxy derivatives (Greer et al., 2007), in the aerial periderm compared to the subterranean periderm. The aerial portion of rutabaga is most likely derived from the hypocotyl rather than the root proper. These alkanes are considered "classic" cuticular waxes, and the aerial loads are at least equivalent to those found on leaves of close relative, rapeseed (Holloway et al., 1977). TEM analysis clearly demonstrated these cells were suberized. Alkanes have been reported in Arabidopsis root waxes (Kosma et al., 2012; Li et al., 2007a) and the suberized periderm of potato (Solanum tuberosum L.) tubers (Schreiber et al., 2005; Serra et al., 2010; Serra et al., 2009). Botanically speaking, potato tubers are modified stems. The implication is that alkane synthesis occurs in these periderm cells. This requires substantiation and then investigation of the temporal regulation with respect to suberin synthesis. The 
extent to which residual alkane levels in the subterranean taproots derive from low levels of biosynthesis by the periderm, or represent small islands of residual epidermis, cortex and endodermis not completely sloughed off during taproot development, remains to be explored.

To extend this comparison, periderm suberin content and composition was determined at three positions along the vertical axis of the rutabaga tuber (Fig. 4, Fig. S3). On a mass per unit surface area basis, the aerial periderm contained a 2-fold or greater sum total of suberin monomers $\left(671 \pm 50 \mu \mathrm{g} \mathrm{cm}^{-2} ; n=4\right)$ than either the subterranean or aerial:subterranean interface (327 \pm 50 and $271 \pm 40$ $\mu \mathrm{g} \mathrm{cm}^{-2}$, respectively; $\left.n=4\right)$. Thus the released suberin aliphatic monomer loads dominated the extractable waxes both above (about 50 -fold) and below ground (about 250-fold). Suberin composition also varied along the vertical axis of the tuber. In general, subterranean periderm suberin tended toward higher proportions of $\omega$-oxidized oleic acid derivatives, namely 18 -hydroxyoleate $(\omega-\mathrm{OH}$ 18:1) and octadec-9-ene-1,18-dioate (18:1 DCA) and their photo-oxidation products (see subsequent sections). Aerial periderm tissues were slightly enriched in very-long-chain fatty acids (C20:0 and C22:0). Overall, ferulate levels were low (2-3 mol \%). Acid-catalyzed transmethylation of suberized tissues has been shown to more effectively release suberin-associated caffeate (Kosma et al., 2012). Given the predominance of alkyl caffeate esters in root periderm waxes of rutabaga, it was logical to determine if caffeate comprised any substantial fraction of polymerized suberin. However, caffeate comprised $<0.5$ mol \% of rutabaga's periderm suberin monomers (Fig. S3). With the exception of 
caffeate and the photo-oxidation products, results were comparable, in terms of relative and quantitative suberin monomer content and composition, when acid or base-catalyzed transmethylation was used to affect depolymerization (Fig. S3).

\subsection{Identification of Suberin Monomers in Rutabaga Taproot Periderm Derived from Oleate with a Structural Motif Suggestive of Photo-Oxidation.}

Unexpected C18 monounsaturated monomers were encountered in the suberin analysis of rutabaga periderm. 9-Hydroxyoctadec-10-ene-1,18-dioic acid, 10,18-dihydroxyoctadec-8-enoic acid and 9,18-dihydroxyoctadec-10-enoic acid were identified based primarily on mass spectra of silylated fatty acid methyl esters (FAMEs) released by base-catalyzed transmethylation (Fig. 5). Their relative GC retention times are consistent with their proposed structures. Double bond positions are based on the absence of one of a pair of possible radical cation cleavages on either side of the mid-chain trimethylsiloxymethine group. The juxtaposition of the double bond $\alpha$ - to this group strongly favors the cleavage that produces a stabilized cation. Thus, $\mathrm{R}_{1} \mathrm{CH}_{2}-\mathrm{CH}(\mathrm{OTMSi})-\mathrm{CH}=\mathrm{CHCH}_{2} \mathrm{R}_{2}$ produces ${ }^{+} \mathrm{CH}(\mathrm{OTMSi}) \mathrm{CH}=\mathrm{CHCH}_{2} \mathrm{R}_{2}$ but negligible $\mathrm{R}_{1} \mathrm{CH}_{2} \mathrm{CH}(\mathrm{OTMSi})^{+}$. The geometric configuration of the double bond was determined to be primarily trans based on chromatographic evidence from standards. The relative retention times and abundance of cis versus trans stereoisomers were determined for the TMSi ethers of $\mathrm{NaBH}_{4}$-reduced photo- and auto-oxidative products of methyl oleate and dimethyloctadec-9-ene-1,18-oate (Fig. S4). a-Hydroxy-cis-ene products elute 
ahead of the corresponding trans-ene products on non-polar columns, as is the case for the simpler methyl octadecenoates (Barve et al., 1972; Fig. S5).

The three major products shown in Fig. 5 have the structures expected for photo-oxidation at the $\mathrm{C}(9)-\mathrm{C}(10)$ cis-double bond once the intermediate hydroperoxide is reduced to a hydroxyl. The symmetry of dimethyloctadec-9-ene1,18-dioate substrate will result in only a single isomeric product, whereas 18 hydroxyoleate will give two isomers. For monoene auto-oxidation about half the hydroxy-ene products are identical to those from photo-oxidation, but the remaining hydroxy-ene isomers retain their original double bond position, along with substantial retention of cis-stereochemistry (Gunstone, 1984). The low abundance of 11- and 8-hydroxy products in the suberin analysis is strongly indicative of a dominant photo-oxidative process over an auto-oxidative process (Fig. S6). This low abundance of 11- and 8-hydroxy products was confirmed by comparison to autoxidized and photo-oxidized methyl oleate and dimethyl-1,18octadec-9-eneoate standards (Fig. S4). Collectively, 9-hydroxyoctadec-10-ene1,18-dioic acid, 10,18-dihydroxyoctadec-8-enoic acid and 9,18-dihydroxyoctadec10-enoic acid comprised 4,10 and 11 mol\% of total suberin in subterranean, interface and aerial regions, respectively. Moreover, they comprised 6, 19 and 27 mol\% of total C18:1 monomers of subterranean, interface and aerial periderm suberin, respectively. Their greater abundance in the aerial region is consistent with a photo-oxidative origin. As a reducing agent was not specifically added during the $\mathrm{NaOMe-catalyzed} \mathrm{transmethylation} \mathrm{and} \mathrm{silylation} \mathrm{procedures,} \mathrm{it} \mathrm{was}$ considered that hydroperoxides, the direct products of photo-oxidation of oleate- 
derived suberin monomers, might not be identified by our analyses. To further determine whether hydroperoxide-containing monomers were present in native suberin, reductive depolymerization was performed on the same periderm peels employed for transmethylation analysis (Fig. S7). Hydrogenolysis using $\mathrm{LiAlH}_{4}$ will produce a single product, 1,9,18-trihydroxyoctadec-10-ene, but information about the reactants can be retained using deuterolysis (Walton and Kolattukudy, 1972), so LiAlD 4 was used. It would be expected that if substantial hydroperoxides were present in native suberin then the amount of C18:1 triol produced by deuterolysis relative to the $\mathrm{C} 18: 1$ diol would indicate substantially greater photo-oxidation when compared to the mid-chain hydroxy fatty acids released from transmethylation. Deuterolysis did not, however, release any additional amounts of triol, but did support the notion of increased photooxidation in the aerial portion of the taproot (Fig S7).

Photo-oxidation products of 18-hydroxyoleate were previously reported for cutin monomers of parsley (Petroselinum sativum) leaves, but only after prolonged irradiation with high intensity visible light (Rontani et al., 2005). Over $90 \%$ of the photo-oxidation products were present in planta as $9(10)$ hydroperoxides, with the remainder being 9(10)-hydroxy compounds. However, as the leaves were detached then irradiated for several weeks, they must be considered a highly senescing tissue. In the aerial periderm of rutabaga, it appears that up to $25 \%$ of oleate-derived suberin monomers have a novel $\alpha$ hydroxy-trans-ene motif from oxygen addition at either carbon of the double bond with concomitant double bond migration and isomerization. The lack of positional 
selectivity is one argument for a possible non-enzymatic process. These results suggest that the majority, if not all, of the $\omega$-oxidized C18:1 photo-oxidation products present in periderm suberin were 9(10)-hydroxy-10(8)-ene fatty acids and not the corresponding hydroperoxides. From this observation, the presence of alkyl hydroperoxide reductase activity acting upon the hydroperoxides can be inferred. Because the amount of these products is much greater in the aerial rather than the subterranean periderm, a likely biosynthetic mechanism is photooxidation via singlet oxygen production, although it cannot be ruled out, for example, that there is a novel form of lipoxygenase or peroxidase. If photooxidation occurs perhaps the cellular mechanisms to clear singlet oxygen production in plastids are not completely effective and perhaps biosynthesis of cutin (monomers) does not occur in membranes where effective ROS scavenging is to be expected. To the best of our knowledge, this is the first demonstration of photo-oxidation-like products of $\omega-\mathrm{OH}$ 18:1 and 18:1 DCA in a native suberin. The loss of these monomers with depolymerization via acidcatalyzed transmethylation may have result in their underestimation in previous studies on cutin and suberin.

\subsection{Root Waxes: Contents and Compositions from Eleven Plant Species}

Root wax screening was conducted by rapid immersion of roots in chloroform and silylation of the recovered extract prior to GC-MS analysis. For most species, $>65 \%$ of the total ion current (TIC) could be assigned to known compounds (Fig. 6b). Maize and sweet potato extracts were the exceptions; 
identifiable peaks represented $30 \%$ and $41 \%$ of the TIC, respectively. Unidentified constituents of maize root waxes comprised mostly low molecular weight compounds (MW of TMSi-ethers $<250$ ). Sweet potato wax extracts were dominated by a single constituent that represented $50 \%$ of the TIC. GC-MS analysis of underivatized, acetylated, and silylated samples suggested the molecular formula as $\mathrm{C}_{30} \mathrm{H}_{50} \mathrm{O}$. That is, the compound is likely to be a $\mathrm{C} 30: 2$ sterol or triterpenoid. The spectrum for this compound did not match spectra for other C30:2 sterols like obtusifoliol or lanosterol nor common triterpenoids like $\beta$ amyrin.

Total wax amounts expressed as mass per unit fresh weight or per unit surface area varied considerably between species (Table 1). Unknowns were included in total wax sums (TIC). No consistent relationship between total wax content and plant family could be observed. The range of total wax per gram of fresh weight was $0.36-422 \mu \mathrm{g} \mathrm{g}^{-1} \mathrm{FW}$ with the lowest amount from extracts of subterranean portion of radish and the largest amount from root extracts of Arabidopsis and then from salt cress. These highest values reflect the high surface area to fresh weight ratios of roots from these species. Excluding maize and rice, where it was not possible to make estimates of root surface area, the total wax amount per unit surface area varied across species considerably less than total wax amount per unit fresh weight. Wax amount per unit surface area ranged from $0.16-5.7 \mu \mathrm{g} \mathrm{cm}^{-2}$. Total extracted wax mass was not strongly related to total surface area $\left(r^{2}=0.4\right)$, total fresh weight $\left(r^{2}=0.24\right)$, or surface area to fresh weight ratio $\left(r^{2}=0.05\right)$. 
Sterols were the only root wax constituents common to all species analyzed. $\beta$-sitosterol (C29:1 sterol) and campesterol (C28:1 sterol) were ubiquitous. $\beta$-sitosterol was the predominant sterol of all of Brassicaceae analyzed, whereas stigmasterol (C29:2 sterol) predominated the sterol profile of all other species analyzed with the exception of sweet potato (Ipomoea batatas L. cv. Beauregard). Biosynthetically, sterols are unrelated to the aliphatic wax and suberin components and their amounts must be regulated to maintain membrane homeostasis. However, alkanes and very long chain fatty acids at least share the fatty acid chain elongation pathway with some aliphatic suberin monomers, as demonstrated by a study of StKCS6 gene silencing in potato (Serra et al., 2009). Alkanes were detected in 6 of the 11 species analyzed in this study albeit at very small proportions in radishes (Fig. 6).

Free fatty acids were present in all species analyzed except radish. They were always saturated, and had chain lengths falling within a C16-C30 range. Excepting $\mathrm{C} 16: 0$ and $\mathrm{C} 18: 0$, free fatty acid chain lengths correlated well with the fatty acyl chain lengths of MAGs. For example, sweet potato MAGs contained C26-C30 acyl chains with a distribution similar to that of C26-C30 free fatty acids. No MAGs were detected in carrot ( $D$. carota L. cv. Danver), pea ( $P$. sativum $L$. cv. Little Marvel), or salt cress extracts. Radishes, on the other hand, had little if any free fatty acids but contained a substantial portion of MAGs (4-14 mol \%). Maize and rice root-wax extracts also possessed MAGs with very-long-chain $\omega$ hydroxy fatty acids ( $\omega$-OH MAGs) representing between 2 and 24 mol \% of total identified waxes, respectively (Fig. 6A). Maize $\omega$-OH MAGs had acyl chain 
lengths of even numbers from C22 to C26; in rice, acyl chain lengths ranged from C24 to C28 (Fig. 7). When present, MAGs occurred as both $\alpha$ - and $\beta$-isomers.

Saturated fatty alcohols were present in all root extracts with the exception of carrots (Fig. 6a). Carbon chain lengths ranged from C16 to C28 but C18-C22 fatty alcohols were the dominant chain lengths for most species analyzed. Exceptions included rice and peas, in which C28 and C26 were the dominant chain lengths of fatty alcohols, respectively. C16 fatty alcohols were found in moderate quantities (2-4 mol \%) in sweet potato and rutabaga waxes. Odd-chain length fatty alcohols (C17, C19, C21, and C25) were found in the wax extracts of several species, including rutabaga, tobacco (Nicotiana tabacum L. cv. Petit Havana), salt cress, and maize, but were typically low in abundance. Although carrot root wax extracts contained no fatty alcohols, they did contain a relatively large proportion the $\mathrm{C} 17$ polyacetylenic alcohols (Fig. S6) falcarinol [(3S,9Z)heptadeca-1,9-dien-4,6-diyn-3-ol)] and falcarindiol [(3R,8S,9Z)-heptadeca-1,9dien-4,6-diyne-3,8-diol], at 8 and $28 \mathrm{~mol} \%$ of total identified waxes, respectively (Yates and England, 1982).

Four of the species described herein were previously analyzed by Espelie et al. (1980). These include carrot, rutabaga, beet and sweet potato. However, the nature of the analyses utilized by Espelie et al. (fractionation and GC with packed columns) will likely have missed many of the larger molecular weight components found in periderm-associated waxes (i.e. MAGs, sterols, and alkyl hydroxycinnamates). Take potato (S. tuberosum) as a case in point. The composition of potato tuber waxes is well established (Schreiber et al. 2005; 
Soler et al. 2009,2010); wax loads range between $10-50 \mathrm{ug} \mathrm{cm}^{-2}$ with alkyl ferulates comprising roughly $40 \%$ of total periderm waxes. Espelie et al. (1980) present potato periderm wax loads of $2 \mathrm{ug} \mathrm{cm}^{-2}$ without any report of alkyl ferulates. Coating root crops with paraffin waxes to improve storability has been implemented in agriculture since the 1940's (Bai and Plotto, 2011). Paraffins are mostly comprised of $n$-alkanes but can also contain branched-chain alkanes and cycloalkanes amongst other constituents (Turner et al., 1955). Since all of the tubers and taproots utilized by Espelie et al. (1980) were purchased from a supermarket, it thus stands to reason that some of their presented results may reflect applied paraffin waxes rather than [or in addition to] endogenous taproot waxes. Espelie et al. (1980) also analyzed parsnip (Pastinaca sativa) and turnip (Brassica rapa subsp. rapa) taproots for their wax content and composition. Alkanes represented the largest proportion ( $\geq 50 \%$ ) parsnip and turnip waxes. Despite the fact that parsnip is a close relative of carrot, no polyacetylenic alcohols were reported for either carrot or parsnip taproot waxes (Espelie et al., 1980). It is well established that cultivated members of the Apiaceae, including parsnip, contain polyacetylenic alcohols (Zidorn et al., 2005) In some instances our data closely matched the data presented by Espelie et al. (1980). For example, the sweet potato data contained herein was very similar to that presented by Espelie et al. (1980) with a few exceptions (Fig. 6, Supplemental File 1); Espelie et al. (1980) reported $45 \%$ of sweet potato waxes to be comprised of fatty alcohols whereas $50 \mathrm{~mol} \%$ of sweet potato waxes were encountered here as alkyl hydroxycinnamates. This discrepancy could be 
explained by hydrolysis of alkyl hydroxycinnamate waxes in the Espelie et al. (1980) study.

\subsection{Root Waxes: Detailed Analysis of AHC Molecular Species from Eleven Plant Species}

Alkyl hydroxycinnamates $(\mathrm{AHC})$ were present in root wax extracts from 10 of the 11 species analyzed, with their content varying from 5 - 93 mol\% of the sum total of identified constituents. Carrot was the only species analyzed that did not possess AHCs. Similar to total wax amount, no trends were evident between sum total $\mathrm{AHC}$ content (mass of $\mathrm{AHCs}$ per unit area or per unit fresh weight) and plant family or root growth form (tuberous or non-tuberous) (Table 2). However, supportive of a superficial association, total extracted AHC mass was highly correlated with root surface area $\left(r^{2}=0.9\right)$ but not fresh weight $\left(r^{2}=0.2\right)$ or root surface area to fresh weight ratio $\left(r^{2}<0.01\right)$. The hydroxycinnamate composition of AHCs varied considerably from species to species (Fig. 8). Cruciferae were dominated by either alkyl caffeates or alkyl coumarates and contained little if any alkyl ferulate esters. Tobacco, maize, and rice AHCs were comprised exclusively of alkyl ferulates, whereas pea AHCs were comprised solely of alkyl coumarates. Sweet potato was the only species with significant proportions of all three AHC classes (70\% alkyl coumarates, 15\% alkyl ferulates and 15\% alkyl caffeates). Beets were unique in possessing only alkyl ferulates (88\%) and alkyl caffeates (12\%) but not alkyl coumarates. Lesser compositional differences between aerial 
and subterranean portions of tuberous taproots were also evident at the level of the AHC class.

AHC alkyl chain lengths were largely restricted to even-numbered C18C22 containing molecular species (Table 3). Sweet potato presented one exception; C16-containing species represented 66 mol\% of total AHCs. Rice root waxes were a second exception, containing even-numbered C20-C28 alkyl ferulates with chain lengths $\geq$ C24 representing $85 \mathrm{~mol} \%$ of total AHCs. Alkyl caffeates with odd-numbered alkyl chain lengths $(\mathrm{C} 17, \mathrm{C} 19$, and $\mathrm{C} 21)$ were present in root waxes of several members of the Brassicaceae, but low in abundance $(<2.5 \%)$. Tobacco was the only species that possessed AHCs with an odd-chain (C21) alkyl group of any substantial proportion (21 mol\% heneicosyl ferulate). Similarly, potato (another solanaceous species) is reported to have periderm alkyl ferulate waxes comprised of roughly $40 \%$ odd-numbered carbon chain lengths (Schreiber et al., 2005). When multiple classes of AHCs were present, alkyl chain length distributions for each hydroxycinnamate class were not always similar. For example, in aerial rutabaga waxes, the C18 to C20 to C22 distribution was $50: 25: 25$ in alkyl coumarates but 8:54:38 in alkyl caffeates. All AHC homologs were present as both cis and trans stereoisomers with trans isomers predominating. For the major AHCs, cis isomers were typically less than $15 \%$.

Little is known about AHC chemotaxonomy, localization and specific function. The fact that carrots were devoid of AHCs implies that these compounds are non-essential to plant taproot growth and development. 
Furthermore, individual classes of AHCs (i.e. caffeates, coumarates or ferulates) were wholly absent from many of the species (Table 3 and Fig. 8), implying that each $\mathrm{AHC}$ class is non-essential. Carrot root waxes are indeed the compositional outlier of all the plants we examined, containing only free fatty acids, sterols, and polyacetylenic alcohols. Carrot was the only species analyzed to be completely devoid of fatty alcohols or of AHCs. As fatty alcohols are one of the substrates for HXXXD-motif/BAHD acyltransferases, their absence would preclude carrots from the capacity to synthesize AHCs. This was somewhat surprising as the periderm of carrots is reported to contain covalently-linked C18-C22 fatty alcohols typical of suberin (Kolattukudy et al., 1975).

Within the Brassicaceae family, root wax AHC compositions show some consistency. The family Brassicaceae is a member of the order Rosales. The only other member of this order analyzed, pea, fits within the compositional criteria for the Brassicaceae; an AHC composition dominated by either alkyl coumarates and/or alkyl caffeates, with very little if any alkyl ferulates, and with alkyl group chain lengths ranging from $\mathrm{C} 18$ to $\mathrm{C} 22$. Most of the other species analyzed, admittedly rather limited in number, show alkyl ferulates as the dominant or only $\mathrm{AHC}$ class. Furthermore, $\mathrm{AHC}$ alkyl chain length is not restricted to $\mathrm{C} 18-\mathrm{C} 22$. In sweet potato, $\mathrm{C} 16$ is the dominant chain length, while for rice C26 and C28 are dominant. Another example is potato tuber periderm, where C28 and C30 alkyl ferulates predominate (Schreiber et al., 2005; Serra et al., 2010). It is pertinent to ask if alkyl ferulate biosynthesis straddles both suberin 
and wax synthesis, whereas alkyl coumarates and caffeates arose later in evolution to provide a more unique and functional wax composition.

Distinct HXXXD-motif/BAHD acyltransferases are highly specific for the synthesis of alkyl ferulates (Gou et al., 2009; Molina et al., 2009; Serra et al., 2010) and alkyl caffeates (Kosma et al., 2012), with the inference, at least for Arabidopsis, that there must be another enzyme/gene specific for alkyl coumarate synthesis (Molina and Kosma, 2014). This proliferation of specific enzymes/genes implies that precise biological control of specific AHC composition is important for function. Differential gene expression could be one mechanism by which different distributions of AHCs are found in aerial and subterranean surfaces of taproots (Fig. 8). The extent to which AHC profile is coregulated by the availability of caffeoyl-, coumaroyl- and feruloyl-CoA substrates is also unknown.

\subsection{Comments about Intra-Specific Variability of Root Wax Compositions}

Previous root wax analyses (Kosma et al., 2012; Li et al., 2007a; Molina et al., 2009; Vishwanath et al., 2013) taken together with this study provide 7 independent determinations, from our laboratory, of Arabidopsis root wax AHC composition. Collectively, alkyl coumarates represent $44.5 \pm 20.5$ mol\% (range 9$68.5 \mathrm{~mol} \%$ ), ferulates $9.5 \pm 2 \mathrm{~mol} \%$ (range $2-23 \mathrm{~mol} \%$ ), and caffeates $46 \pm 23.5$ mol\% (range 25.5-89.5 mol\%) of root wax AHCs from growth chamber-grown Arabidopsis plants. It seems unlikely that this variance can be accounted for solely by sampling and analytical variance. Differences in growth conditions and 
unperceived stresses will also contribute to the wide differences in $\mathrm{AHC}$ class distributions. Thus, compositional comparisons for root waxes between plant species may also be expected to exhibit wide variances.

From the Brassicaceae, pairs of varieties or subspecies within a single species were analyzed. More specifically, rapeseed (B. napus L. var. napus cv. Westar) was compared to rutabaga (B. napus subsp. rapifera), and radish ( $R$. sativus L. var. sativus cv. French Breakfast) was compared to daikon ( $R$. sativus L. var. niger J. Kern. cv. Mino Early). The non-tuberous taproots of rapeseed had a wax class composition closely resembling the subterranean portion of rutabagas (Fig. 8), and with $\mathrm{AHC}$ compositions that were reasonably well matched (Fig. 8 and Table 3). By contrast, radish shows a complete absence of FFAs while they constitute a significant proportion of daikon root waxes (Fig. 6). Whether the origin of this variation is genetic or environmental remains to be determined, but the difference underscores the difficulties in making exact comparisons for the chemotaxonomy of root waxes. A comparative study of radish and daikon may aid in determining if FFA is a product of (extracellular) MAG hydrolysis or an intracellular very-long-chain acyl-CoA thioesterase.

\section{Conclusions}

This survey of root waxes, that is, lipids extracted by rapid immersion of intact root tissues in chloroform, showed AHCs to be more widespread among higher plants than previously demonstrated. Sterols were ubiquitous, while fatty alcohols, fatty acids and MAGs were present in many species. Sampling above 
or below-ground portions of taproots can result in distinctly different wax compositions and loads per unit surface area. Rutabaga appears to be an excellent system to assess differential suberin-related lipid synthesis in aerial versus subterranean periderm tissues. The suberin of rutabaga periderm was shown to include monomers derived from oleate that appear to have undergone photo-oxidation. As expected, oleate-derived photo-oxidation products were more prevalent in aerial periderm, and appear to be present largely as the reduced product, monomers containing an a-hydroxy-trans-ene motif. Specific functions for root wax classes, and particularly AHCs, are uncertain and details of precise localization unclear. Before undertaking further work on chemotaxonomy, localization and the overlap between suberin and wax biosynthesis, it would be useful to assess the role of environmental and pathogen stress on the levels of AHCs. This would remove variability in the system studied, whereas any progress understanding their function would stimulate research on these enigmatic compounds.

\section{Experimental}

\subsection{Plant material and growing conditions}

All plant species were germinated and grown in a 2:1 (v/v) mixture of potting mix (Pro-Mix BX, Premier Tech Horticulture, Rivière-du-Loup, Québec) and calcined clay granules (PPC Greens Grade, Profile, Buffalo Grove, IL). The following species were screened, with plant age at harvest indicated in 
parentheses: beet, Beta vulgaris L. cv. Detroit Dark Red (86 days); rapeseed, Brassica napus L. var. napus cv. Westar (129 days); carrot, Daucus carota L. cv. Danver (112 days); daikon, Raphanus sativus L. var. niger J. Kern. cv. Mino Early (133 days), maize, Zea mays cv. B73 (102 days); pea, Pisum sativum L. cv. Little Marvel (76 days); radish, Raphanus sativus $L$ var. sativus cv. French Breakfast (63 days); rice, Oryza sativa L. subsp. japonica cv. Nippon Bare (172 days); rutabaga, Brassica napus subsp. rapifera Metzg. (155 days); sweet potato, Ipomoea batatas (L.) Lam. cv. Beauregard (140 days); and tobacco, Nicotiana tabacum L. cv. Petit Havana (62 days). These species were grown under natural light in a greenhouse with climate control systems. Seasonal variations in available light were supplemented with overhead high pressure sodium-vapor, high-intensity discharge lamps, which provided an additional 22 $\mu \mathrm{mol} \mathrm{m} \mathrm{m}^{-2} \mathrm{~s}^{-1}$ of light and an 18-h-light/6-h-dark photoperiod. The temperature ranged from $20^{\circ} \mathrm{C}$ to $30^{\circ} \mathrm{C}$ and relative humidity from $40 \%$ to $60 \%$. Seeds of Arabidopsis thaliana L. ecotype Columbia-0 (42 days) and salt cress, Eutrema salsugineum (Pall.) Al-Shehbaz \& Warwick ecotype Yukon (185 days) were stratified for 2-4 days at $4^{\circ} \mathrm{C}$ and grown in a controlled growth chamber under white fluorescent light $\left(80-100 \mu \mathrm{mol} \mathrm{m}^{-2} \mathrm{~s}^{-1}\right)$ in an 18-h-light/6-h-dark photoperiod at a temperature of $20^{\circ} \mathrm{C}$ to $22^{\circ} \mathrm{C}$ and a relative humidity of 40 to $60 \%$. $E$. salsugineum ecotype Yukon plants were vernalized for approximately 30 days under continuous light to induce flowering.

\subsection{Transmission Electron Microscopy}


For small roots like those of Arabidopsis and salt cress (E. salsigineum), entire taproots were sampled. For rice and maize, approximately $5 \mathrm{~mm}$ sections of whole fibrous roots from within $5 \mathrm{~cm}$ of the root/shoot junction were sampled. For larger taproots, approximately $15 \mathrm{~mm}^{2}$ sections were taken from different areas of the root periderm. 2-3 biological replicates were sampled for each species. The micrographs presented in Figures 1 and 2 are representative of what was observed in these samples. Entire roots or periderm sections were fixed with $0.1 \mathrm{M}$ cacodylate buffer containing $2.5 \%$ glutaraldehyde and $2 \%$ paraformaldehyde, post fixed with $1 \%$ buffered $\mathrm{OsO}_{4}$, and dehydrated through a graded acetone series. Samples were then infiltrated with Poly/Bed 812 resin. After placing in silicone molds, embedded samples were polymerized for $24 \mathrm{~h}$ at $60^{\circ} \mathrm{C}$. Silvergold ultrathin sections were prepared with a diamond knife on a Power Tome_XL microtome (Boeckeler Instruments) and placed on copper-mesh grids. Samples on grids were treated with $10 \% \mathrm{H}_{2} \mathrm{O}_{2}$ for 10 min, and stained with $10 \%$ uranyl acetate in $\mathrm{MeOH}$ for 8 min then Reynold's lead citrate for 10 min. This modified staining procedure enhances the contrast of both cutin and suberin (Heumann, 1990). Specimens were examined with a JEOL 100CX transmission electron microscope, and images processed with Adobe Photoshop CS5.

\subsection{Suberin Composition Analysis}

Periderm peels of Brassica napus subsp. rapifera were ground and delipidated as previously described (Bonaventure et al., 2004). Base-catalyzed transmethylation with $\mathrm{NaOMe}$ was used to affect depolymerization as previously 
described (Bonaventure et al., 2004; Molina et al., 2006) with slight modification. Briefly, delipidated and dried pulverized tissues were heated in $\mathrm{MeOH}$ containing 4.5\% (w/v) NaOMe and $7.5 \%(\mathrm{v} / \mathrm{v}) \mathrm{MeOAc}$ at $60^{\circ} \mathrm{C}$ overnight with periodic vortexing. Methyl heptadecanoate and pentadecalactone were added as internal standards. On cooling, acidification to $\mathrm{pH} 4$ with $\mathrm{AcOH}$ and addition of dilute brine, the monomers were extracted into $\mathrm{CH}_{2} \mathrm{Cl}_{2}$. The organic phase was washed with dilute brine, dried (anhydrous $\mathrm{Na}_{2} \mathrm{SO}_{4}$ ) and evaporated to dryness under $\mathrm{N}_{2}$ gas. Samples were then derivatized with $100 \mu \mathrm{l}$ each of pyridine and $\mathrm{N}, \mathrm{O}-$ bis(trimethylsilyl)trifluoroacetamide (BSTFA) at $100^{\circ} \mathrm{C}$ for 10 min with excess pyridine and BSTFA removed by evaporation. Samples were dissolved in $n$ heptane:toluene (1:1 v/v) for analysis by GC-MS.

Alternatively, reduction with $\mathrm{LiAID}_{4}$ was used to affect depolymerization of delipidated powders from Brassica napus subsp. rapifera periderm, and specifically from the same plants analyzed by transmethylation. To affect deuterolysis, plant tissue $(50 \mathrm{mg})$, methyl heptadecanoate internal standard (50 $\mu \mathrm{g})$ and $\mathrm{LiAlD}_{4}(100 \mathrm{mg})$ were heated at $70^{\circ} \mathrm{C}$ in anhydrous tetrahydrofuran $(6$ $\mathrm{ml}$ ) for 48 hours with periodic vortexing. Reaction mixtures were cooled to room temperature and excess $\mathrm{LiAlD}_{4}$ was quenched by the addition of EtOAC. After acidification to $\mathrm{pH} 2$ with dilute $\mathrm{HCl}$, products were extracted into $\mathrm{Et}_{2} \mathrm{O}$, washed with dilute brine, dried and evaporated under $\mathrm{N}_{2}$. The samples were silylated and analyzed by GC-MS as described above.

GC-MS(electron impact) analysis of silylated depolymerization products from either method used an HP-5MS capillary column with inlet temperature set 
at $330^{\circ} \mathrm{C}$, oven temperature ramped from $140^{\circ} \mathrm{C}$ to $310^{\circ} \mathrm{C}$ at $5^{\circ} \mathrm{C} / \mathrm{min}$, and $\mathrm{MS}$ transfer line at $320^{\circ} \mathrm{C}$.

\subsection{Root Wax Extraction and Analysis}

All roots were cut off $1 \mathrm{~mm}$ above the transition to green stem tissue and gently rinsed clean of soil with tap and then distilled $\mathrm{H}_{2} \mathrm{O}$. For species in which a significant portion of the tuberous taproot protruded above the soil line, aboveground (aerial) and below-ground (subterranean) portions were extracted separately. The extraction was performed by completely submerging the root in $\mathrm{CHCl}_{3}$ for 2 minutes with mild agitation. $\mathrm{CHCl}_{3}$ extracts were filtered and reduced in volume by using a rotary evaporator. Extracts were transferred into glass tubes for evaporation to dryness under nitrogen and dissolved in chloroform. To each sample was added a mixture of internal standards containing heptadecanoic acid, monoheptadecanoin, tricosan-1-ol, $n$-octacosane, tridecyl ferulate and heptadecyl coumarate. The synthesis and purification of tridecyl ferulate and heptadecyl coumarate standards has been described (Kosma et al., 2012). Aliquots were evaporated to dryness and silylated with pyridine $(0.5 \mathrm{~mL})$ and BSTFA $(0.5 \mathrm{~mL})$ at $110^{\circ} \mathrm{C}$ for $10 \mathrm{~min}$. Excess reagents were evaporated under $\mathrm{N}_{2}$ and samples were dissolved in $n$-heptane:toluene (1:1 v/v) for GC-MS analysis using a HP-5MS capillary column (length $30 \mathrm{~m}$, id $0.25 \mathrm{~mm}$, film thickness $0.25 \mu \mathrm{m}, \mathrm{J} \& W$ Scientific). For most samples GC heated zones were set as follows: inlet temperature $350^{\circ} \mathrm{C}$ (splitless injection), oven temperature $130^{\circ} \mathrm{C}$ for 3 minutes and ramped to $325^{\circ} \mathrm{C}$ at $5^{\circ} \mathrm{C} / \mathrm{min}$, then held at $325^{\circ} \mathrm{C}$ for 10 
minutes. The MS transfer line was set at $320^{\circ} \mathrm{C}$. For I. batatas, O. sativa, and $Z$. maize samples inlet temperature was set to $360^{\circ} \mathrm{C}$ while oven temperature was ramped to $345^{\circ} \mathrm{C}$.

Most root wax components were identified based on spectra generated by analysis of standards or from published mass spectra. The polyacetylenes, falcarinol and falcarindiol, were identified from synthetic standards of racemic mixtures. Compounds with identical retention times and mass spectra were treated as falcarinol and falcarindiol.

\subsection{Root Surface Area Determination}

Root surface areas were determined via scanned digital images of whole roots or periderm peels. The software ImageJ (Rasband, 1997) and the tools contained therein were used to measure the lengths and areas of the digitized images. The surface areas of whole taproots was calculated assuming a conical geometry using the formula $\mathrm{SA}=\pi{ }^{*} r^{*} s$ where $r=$ the radius at the cut base of the root surface and $s=$ length of the side of the root. $s$ was taken as the mean length of 2 sides from the digitized two-dimensional image and $r$ was calculated as $1 / 2$ of the measured width at the cut base. For plants with large tuberous roots, such as sweet potato, the surface area was determined from digitized images of periderm peels.

\section{Acknowledgments}


The authors are grateful to John Ohlrogge of Michigan State University for general support and research guidance. The authors acknowledge Alicia Withrow from the Michigan State University Center for Advanced Microscopy for sample preparation and assistance with TEM analyses. Synthetic standards falcarinol and falcarindiol (as racemic mixtures) were kindly provided by Dr. Robert Minto (Department of Chemistry and Chemical Biology; Indiana University-Purdue University, Indianapolis, Indiana, USA). Funding for this research was provided by the National Science Foundation Grant MCB-0615563.

Appendix A. Supplementary data

Supplementary data associated with this article can be found in the online version at http://xxxxxxxx.

\section{Figure Legends}

Figure 1. TEM of cell walls from the periderm and exodermis of plant species investigated in this study demonstrating alternating dark and light bands typical of suberin lamellae. (A, B) exodermis from mature regions of maize (Zea mays cv. B73) and rice (Oryza sativa L. subsp. japonica cv. Nippon Bare), respectively, (C) beet (Beta vulgaris L. cv. Detroit Dark Red), (D) carrot (Daucus carota L. cv. Danver), (E) sweet potato (Ipomoea batatas (L.) Lam. cv. Beauregard), (F) tobacco (Nicotiana tabacum L. cv. Petit Havana), (G) pea (Pisum sativum L. cv. 
Little Marvel), (H) salt cress (Eutrema salsugineum (Pall.) Al-Shehbaz \& Warwick ecotype Yukon), (I) Arabidopsis thaliana L. ecotype Columbia-0, (J,M) radish (Raphanus sativus $L$ var. sativus cv. French Breakfast) aerial and subterranean, respectively, (K, N) daikon (Raphanus sativus L. var. niger J. Kern. cv. Mino Early) aerial and subterranean, respectively, (L) rapeseed (Brassica napus L. var. napus cv. Westar). Scale bars $=100 \mathrm{~nm}$.

Figure 2. (A) Tuberous taproot from 5-month-old rutabaga (Brassica napus supbs. rapifera) plant. TEM of cell wall from (B) aerial, (C) aerial:subterranean interface, and (D) subterranean periderm peels of rutabaga taproot.

Figure 3. Composition of chloroform extractable root waxes from tuberous taproot surfaces of rutabaga (Brassica napus supbs. rapifera). (A) Composition of rutabaga taproot waxes as mass of wax class per unit surface area $\left(\mu \mathrm{g} \mathrm{cm}^{-2}\right)$. (B) Relative composition of individual wax constituents as mol\%. Data are presented as the mean of 4 biological replicates + SD. FFA $=$ free fatty acid, C29 $=n$-nonacosane, $\mathrm{ALDs}=$ aldehydes, MAGs = monoacylglycerols.

Figure 4. Suberin monomer composition of periderm peels from the tuberous taproots of 5-month-old rutabaga (Brassica napus supbs. rapifera). Monomers were released by base-catalyzed transmethylation with sodium methoxide analyzed as trimethylsilyl ether derivatives. Data represent the mean of 4 
biological replicates $+\mathrm{SD} . \mathrm{PPs}=$ phenylpropanoids, $\mathrm{OH}=$ hydroxy, $\mathrm{DCAs}=$ dicarboxylates, $c=$ cis, $t=$ trans.

Figure 5. Reduced forms of $\omega$-hydroxy oleate and octadec-9-ene-1,18-dioate photo-oxidation products are present in rutabaga (Brassica napus supbs. rapifera) suberin and enriched in above-ground periderm. (A) Amounts of dimethyl-9-hydroxy-octadec-trans-10-ene-1,18-dioate (9-OH 18:1 $\Delta 10 t-\mathrm{DCA})$ and methyl-(10)9,18-dihydroxy octadec-trans-(8)10-enoate [(10)9,18-diOH 18:1 $\Delta 8(10) t]$ found in suberin extracts from different positions along the vertical axis of the rutabaga periderm (data are mean values $+\mathrm{SD}, n=.4$ ) (B) Partial chromatogram from total ion current (TIC) and single ion monitoring (SIM) of diagnostic fragments. (C,D) Molecular structure, electron-impact mass spectra, and major fragmentation of methyl-(10)9,18-dihydroxy octadec-trans-(8)10enoate and dimethyl-9-hydroxy-octadec-trans-10-ene-1,18-dioate, respectively. Monomers were released by sodium-methoxide catalyzed transmethylation and analyzed as TMSi-ether derivatives.

Figure 6. (A) Relative composition of wax classes detected in chloroform dip extracts from 11 plant species. Data are presented as the sum total mole percent of individual constituents within each class. Mole percent data were calculated from the sum total amounts of identified constituents. (B) Percent of identified and unidentified constituents calculated based on mass per unit of fresh weight 
( $\left.\mu \mathrm{g} \mathrm{g}^{-1} \mathrm{FW}\right)$. Plant species analyzed: see section 4.1 or Figure 1 legend for Latin names. MAGs $=$ monoacylglycerols, $\mathrm{OH}=$ hydroxy .

Figure 7. $\omega$-Hydroxy monoacylglycerol ( $\omega$-OH MAGs) content of rice (Oryza sativa L. subsp. japonica cv. Nippon Bare) and maize (Zea mays cv. B73). (A) Mass per unit of root fresh mass $\left(\mu \mathrm{g} \mathrm{g}^{-1} \mathrm{FW}\right)$. Data are presented as mean values + SD from 3-4 biological replicates.

Figure 8. Percent composition of alkyl hydroxycinnamate (AHC) classes (with respect to phenylpropanoid head group) for all species analyzed in this study. Percent values were calculated from total AHC contents (nmols). Plant species analyzed: see section 4.1 or Figure 1 legend for Latin names. 


\section{Table Legends}

Table 1. Total amount of wax constituents extracted by rapid immersion of roots in chloroform. Data represent the mean \pm SD of 3-4 biological replicates. Amounts are presented as sum totals of constituents from mass per unit area $(\mu \mathrm{g}$ $\mathrm{cm}^{-2}$ ) and mass per unit of fresh root mass $\left(\mu \mathrm{g} \mathrm{g}^{-1} \mathrm{FW}\right) . \mathrm{N} / \mathrm{D}=$ not determined. *Determined in a separate experiment. Plant species analyzed: see section 4.1 or Figure 1 legend for Latin names.

Table 2. Total amounts of alkyl hydroxycinnamates for each species analyzed. Amounts are presented as sum totals of constituents from mass per unit area $(\mu \mathrm{g}$ $\left.\mathrm{cm}^{-2}\right)$ and mass per unit of fresh root mass $\left(\mu \mathrm{g} \mathrm{g}^{-1} \mathrm{FW}\right)(n=3-4 \pm \mathrm{SD})$. *Determined in a separate experiment. Plant species analyzed: see section 4.1 or Figure 1 legend for Latin names.

Table 3. Percent alkyl chain length distribution of alkyl hydroxycinnamates for each species analyzed. Percent values for each specific chain length were calculated from total AHC class amounts (nmols). - = not detected. Plant species analyzed: see section 4.1 or Figure 1 legend for Latin names. 


\section{References}

Bai, J., Plotto, A., 2011. Coatings for fresh fruits and vegetables, in: Baldwin, E.A., Hagenmaier, R., Bai, J. (Eds.), Edible Coatings and Films to Improve Food Quality. Boca Raton, pp. 185-242.

Barve, J., Gunstone, F., Jacobsberg, F., Winlow, P., 1972. Fatty acids, part 34 behaviour of all the methyl octadecenoates and octadecynoates in argentation chromatography and gas-liquid chromatography. Chem. Phys. Lipids 8, 117-126.

Beisson, F., Li, Y., Bonaventure, G., Pollard, M., Ohlrogge, J. B., 2007. The acyltransferase gpat5 is required for the synthesis of suberin in seed coat and root of Arabidopsis. Plant Cell 19, 351-368.

Bernards, M. A., Lewis, N. G., 1992. Alkyl ferulates in wound healing potato tubers. Phytochemistry 31, 3409-3412.

Boher, P., Serra, O., Soler, M., Molinas, M., Figueras, M., 2013. The potato suberin feruloyl transferase fht which accumulates in the phellogen is induced by wounding and regulated by abscisic and salicylic acids. J. Exp. Bot. 64, 32253236.

Bonaventure, G., Beisson, F., Ohlrogge, J., Pollard, M., 2004. Analysis of the aliphatic monomer composition of polyesters associated with Arabidopsis epidermis: Occurrence of octadeca-cis-6, cis-9-diene-1,18-dioate as the major component. Plant J. 40, 920-930. 
Domergue, F., Vishwanath, S. J., Joubes, J., Ono, J., Lee, J. A., Bourdon, M., Alhattab, R., Lowe, C., Pascal, S., Lessire, R., Rowland, O., 2010. Three Arabidopsis fatty acyl-coenzyme a reductases, far1, far4, and far5, generate primary fatty alcohols associated with suberin deposition. Plant Physiol. 153, 1539-1554.

Espelie, K. E., Sadek, N. Z., Kolattukudy, P. E., 1980. Composition of suberinassociated waxes from the subterranean storage organs of seven plants, parsnip, carrot, rutabaga, turnip, red beet, sweet potato and potato. Planta 148, 468-476.

Freire, C. S. R., Silvestre, A. J. D., Neto, C. P., 2007. Demonstration of longchain $n$-alkyl caffeates and d7-steryl glucosides in the bark of acacia species by gas chromatography-mass spectrometry. Phytochem. Anal. 18, 151-156.

García-Argáez, A. N., Pérez-Amador, M. C., Aguirre-Hernández, E., MartínezVázquez, M., 1999. Two new caffeate esters from roots of Merremia tuberosa and M. dissecta. Planta Med. 65, 678,679.

Gou, J. Y., Yu, X. H., Liu, C. J., 2009. A hydroxycinnamoyltransferase responsible for synthesizing suberin aromatics in Arabidopsis. Proc. Natl. Acad. Sci. U. S. A. 106, 18855-18860.

Greer, S., Wen, M., Bird, D., Wu, X., Samuels, L., Kunst, L., Jetter, R., 2007. The cytochrome p450 enzyme cyp96a15 is the midchain alkane hydroxylase 
responsible for formation of secondary alcohols and ketones in stem cuticular wax of Arabidopsis. Plant Physiol. 145, 653-667.

Gunstone, F., 1984. Reaction of oxygen and unsaturated fatty acids. Journal of the American Oil Chemists' Society 61, 441-447.

Gutiérrez Suárez, A., Río Andrade, J. C. d., Rodríguez García, M. I., 2004. Identification of intact long-chain $p$-hydroxycinnamate esters in leaf fibers of abaca (Musa textilis) using gas chromatography/mass spectrometry. Rapid Communications in Mass Spectrometry 2696, 2691-2696.

Heumann, H. G., 1990. A simple method for improved visualization of the lamellated structure of cutinized and suberized plant cell walls by electron microscopy. Stain Technol 65, 183-187.

Holloway, P. J., Brown, G. A., Baker, E. A., Macey, M. J. K., 1977. Chemical composition and ultrastructure of the epicuticular wax in three lines of Brassica napus (I). Chem. Phys. Lipids 19, 114-127.

Kawanishi, K., Yasufuku, J., Ishikawa, A., Hashimoto, Y., 1990. Long-chain alkyl ferulates in three varieties of Ipomoea batatas (I.) lam. J. Agric. Food Chem. 38, 105-108.

Kolattukudy, P. E., Kronman, K., Poulose, A. J., 1975. Determination of structure and composition of suberin from roots of carrot, parsnip, rutabaga, turnip, red beet, and sweet-potato by combined gas-liquid-chromatography and massspectrometry. Plant Physiol. 55, 567-573. 
Kosma, D. K., Molina, I., Ohlrogge, J. B., Pollard, M., 2012. Identification of an Arabidopsis fatty alcohol: Caffeoyl-Coenzyme A acyltransferase required for the synthesis of alkyl hydroxycinnamates in root waxes. Plant Physiol. 160, 237-248.

Li, Y., Beisson, F., Ohlrogge, J., Pollard, M., 2007a. Monoacylglycerols are components of root waxes and can be produced in the aerial cuticle by ectopic expression of a suberin-associated acyltransferase. Plant Physiol. 144, 12671277.

Li, Y. H., Beisson, F., Koo, A. J. K., Molina, I., Pollard, M., Ohlrogge, J., 2007b. Identification of acyltransferases required for cutin biosynthesis and production of cutin with suberin-like monomers. Proc. Natl. Acad. Sci. U. S. A. 104, 1833918344.

Molina, I., Bonaventure, G., Ohlrogge, J., Pollard, M., 2006. The lipid polyester composition of Arabidopsis thaliana and Brassica napus seeds. Phytochemistry 67, 2597-2610.

Molina, I., Kosma, D., 2014. Role of HXXXD-motif/BAHD acyltransferases in the biosynthesis of extracellular lipids. Plant Cell Rep. doi:10.1007/s00299-0141721-5

Molina, I., Li-Beisson, Y., Beisson, F., Ohlrogge, J. B., Pollard, M., 2009. Identification of an Arabidopsis feruloyl-coenzyme a transferase required for suberin synthesis. Plant Physiol. 151, 1317-1328. 
Rontani, J. F., Rabourdin, A., Pinot, F., Kandel, S., Aubert, C., 2005. Visible lightinduced oxidation of unsaturated components of cutins: A significant process during the senescence of higher plants. Phytochemistry 66, 313-321.

Santos, S., Schreiber, L., Graca, J., 2007. Cuticular waxes from ivy leaves (Hedera helix I.): Analysis of high-molecular-weight esters. Phytochem. Anal. 18, 60-69.

Schmutz, A., Jenny, T., Ryser, U., 1994. A caffeoyl fatty-acid glycerol ester from wax associated with green cotton fiber suberin. Phytochemistry 36, 1343-1346.

Schreiber, L., Franke, R., Hartmann, K., 2005. Wax and suberin development of native and wound periderm of potato (Solanum tuberosum I.) and its relation to peridermal transpiration. Planta 220, 520-530.

Serra, O., Hohn, C., Franke, R., Prat, S., Molinas, M., Figueras, M., 2010. A feruloyl transferase involved in the biosynthesis of suberin and suberinassociated wax is required for maturation and sealing properties of potato periderm. Plant J. 62, 277-290.

Serra, O., Soler, M., Hohn, C., Franke, R., Schreiber, L., Prat, S., Molinas, M., Figueras, M., 2009. Silencing of stkcs6 in potato periderm leads to reduced chain lengths of suberin and wax compounds and increased peridermal transpiration. J. Exp. Bot. 60, 697-707.

Sun, W.-X., Zhang, Q., Jiang, J.-Q., 2006. Chemical constituents of Daphne giraldii Nitsche. Journal of Integrative Plant Biology 48, 1498-1501. 
Turner, W.R., Brown, D.S., Harrison, D.V., 1955. Properties of paraffin waxes. Industrial \& Engineering Chemistry 47, 1219-1226.

Vishwanath, S. J., Kosma, D. K., Pulsifer, I. P., Scandola, S., Pascal, S., Joubès, J., Dittrich-Domergue, F., Lessire, R., Rowland, O., Domergue, F., 2013. Suberin-associated fatty alcohols in Arabidopsis thaliana: Distributions in roots and contributions to seed coat barrier properties. Plant Physiol. 163, 1118-1132.

Walton, T. J., Kolattukudy, P. E., 1972. Determination of the structures of cutin monomers by a novel depolymerization procedure and combined gas chromatography and mass spectrometry. Biochemistry 11, 1885-1896.

Yang, W., Pollard, M., Li-Beisson, Y., Beisson, F., Feig, M., Ohlrogge, J., 2010. A distinct type of glycerol-3-phosphate acyltransferase with sn-2 preference and phosphatase activity producing 2-monoacylglycerol. Proc. Natl. Acad. Sci. U. S. A. $107,12040-12045$.

Yang, W. L., Simpson, J. P., Li-Beisson, Y., Beisson, F., Pollard, M., Ohlrogge, J. B., 2012. A land-plant-specific glycerol-3-phosphate acyltransferase family in Arabidopsis: Substrate specificity, sn-2 preference, and evolution. Plant Physiol. $160,638-652$.

Yates, S. G., England, R. E., 1982. Isolation and analysis of carrot constituents: Myristicin, falcarinol, and falcarindiol. J. Agric. Food Chem. 30, 317-320. 
Yunoki, K., Musa, R., Kinoshita, M., Tazaki, H., Oda, Y., Masao, O., 2004.

Presence of higher alcohols as ferulates in potato pulp and its radical-scavenging activity. Bioscience Biotechnology and Biochemistry 68, 2619-2622.

Zidorn, C., Jöhrer, K., Ganzera, M., Schubert, B., Sigmund, E.M., Mader, J., Greil, R., Ellmerer, E.P., Stuppner, H., 2005. Polyacetylenes from the Apiaceae vegetables carrot, celery, fennel, parsley, and parsnip and their cytotoxic activities. J. Agric. Food Chem. 53, 2518-2523. 
Table 1. Total amount of wax constituents extracted by rapid immersion of roots in chloroform. Data represent the mean \pm SD of 3-4 biological replicates. Amounts are presented as sum totals of constituents from mass per unit area $\left(\mu \mathrm{g} \mathrm{cm}^{-2}\right)$ and mass per unit of fresh root mass $\left(\mu \mathrm{g} \mathrm{g}^{-1} \mathrm{FW}\right)$. N/D = not determined. *Determined in a separate experiment. Plant species analyzed: see section 4.1 or Figure 1 legend for Latin names.

\begin{tabular}{|c|c|c|}
\hline Species Common Name & $\mu \mathrm{g} \mathrm{cm}{ }^{-2}$ & $\mu g g^{-1} F W$ \\
\hline Maize & $\mathrm{N} / \mathrm{D}$ & $39.72 \pm 7.01$ \\
\hline Rice & $N / D$ & $13.60 \pm 4.66$ \\
\hline Beet & $0.78 \pm 0.10$ & $0.93 \pm 0.22$ \\
\hline Carrot & $0.41 \pm 0.16$ & $0.78 \pm 0.28$ \\
\hline Sweet Potato & $3.62 \pm 1.32$ & $5.66 \pm 3.04$ \\
\hline Tobacco & $0.82 \pm 0.13$ & $5.78 \pm 1.30$ \\
\hline Pea & $0.16 \pm 0.03$ & $2.49 \pm 0.44$ \\
\hline Salt Cress & $2.07 \pm 0.82$ & $76.87 \pm 27.19$ \\
\hline Arabidopsis & $5.62 \pm 0.60$ & $421.97 \pm 61.55$ \\
\hline Radish Aerial & $0.50 \pm 0.18$ & $0.64 \pm 0.14$ \\
\hline Radish Subterranean & $0.38 \pm 0.11$ & $0.36 \pm 0.10$ \\
\hline Daikon Aerial & $1.38 \pm 0.55$ & $1.20 \pm$ \\
\hline Daikon Subterranean & $1.60 \pm 0.59$ & $1.68 \pm 0.59$ \\
\hline Rapeseed & $1.33 \pm 0.30$ & $10.97 \pm 0.42$ \\
\hline Rutabaga Aerial & ${ }^{*} 5.65 \pm 1.03$ & $1.10 \pm 0.53$ \\
\hline Rutabaga Interface & ${ }^{*} 1.70 \pm 0.11$ & $N / D$ \\
\hline Rutabaga Subterranean & ${ }^{*} 1.18 \pm 0.10$ & $1.09 \pm 0.39$ \\
\hline
\end{tabular}


Table 2. Total amounts of alkyl hydroxycinnamates for each species analyzed. Amounts are presented as sum totals of constituents from mass per unit area $\left(\mu \mathrm{g} \mathrm{cm}^{-2}\right)$ and mass per unit of fresh root mass $\left(\mu \mathrm{g} \mathrm{g}^{-1} \mathrm{FW}\right)(n=3-4 \pm \mathrm{SD})$. * Determined in a separate experiment. Plant species analyzed: see section 4.1 or Figure 1 legend for Latin names.

\begin{tabular}{|c|c|c|c|c|}
\hline Species Common Name & & $\mathrm{cm}$ & & $\mu \mathrm{g} \mathrm{g}^{-1} \mathrm{FW}$ \\
\hline Maize & $\mathrm{N} / \mathrm{D}$ & \pm & $\mathrm{N} / \mathrm{D}$ & $0.22 \pm 0.17$ \\
\hline Rice & $\mathrm{N} / \mathrm{D}$ & \pm & $\mathrm{N} / \mathrm{D}$ & $3.90 \pm 1.99$ \\
\hline Beet Subterranean & 0.20 & \pm & 0.06 & $0.24 \pm 0.11$ \\
\hline Carrot & $\mathrm{N} / \mathrm{D}$ & \pm & $\mathrm{N} / \mathrm{D}$ & $N / D \pm N / D$ \\
\hline Sweet Potato & 0.65 & \pm & 0.22 & $1.15 \pm 0.59$ \\
\hline Tobacco & 0.05 & \pm & 0.02 & $0.33 \pm 0.17$ \\
\hline Pea & 0.03 & \pm & 0.01 & $0.47 \pm 0.19$ \\
\hline Salt Cress & 1.54 & \pm & 0.65 & $60.90 \pm 23.29$ \\
\hline Arabidopsis & 5.17 & \pm & 0.53 & $388.21 \pm 59.49$ \\
\hline Radish Aerial & 0.12 & \pm & 0.09 & $0.15 \pm 0.09$ \\
\hline Radish Subterranean & 0.07 & \pm & 0.03 & $0.07 \pm 0.03$ \\
\hline Daikon Aerial & 0.16 & \pm & 0.05 & $0.14 \pm 0.05$ \\
\hline Daikon Subterranean & 0.14 & \pm & 0.07 & $0.15 \pm 0.06$ \\
\hline Rapeseed & 0.54 & \pm & 0.12 & $4.48 \pm 0.42$ \\
\hline Rutabaga Aerial & ${ }^{*} 0.53$ & \pm & 0.22 & $0.16 \pm 0.16$ \\
\hline Rutabaga Interface & ${ }^{*} 0.18$ & \pm & 0.05 & $\mathrm{~N} / \mathrm{D}$ \\
\hline Rutabaga Subterranean & ${ }^{*} 0.19$ & \pm & 0.06 & $0.48 \pm 0.29$ \\
\hline
\end{tabular}


Table 3. Percent alkyl chain length distribution of alkyl hydroxycinnamates for each species analyzed. Percent values for each specific chain length were calculated from total AHC class amounts (nmols). - = not detected. Plant species analyzed: see section 4.1 or Figure 1 legend for Latin names.

\begin{tabular}{|c|c|c|c|c|c|c|c|c|c|c|c|c|c|c|c|c|c|c|c|c|c|}
\hline & \multicolumn{21}{|c|}{ Alkyl Group Carbon Chain Length } \\
\hline & \multicolumn{4}{|c|}{ Alkyl Coumarate } & \multicolumn{8}{|c|}{ Alkyl Ferulate } & \multicolumn{9}{|c|}{ Alkyl Caffeate } \\
\hline & C16 & C18 & $\mathrm{C2O}$ & C22 & C16 & C18 & C20 & C21 & $\mathrm{C} 22$ & C24 & C26 & $\mathrm{C} 28$ & C16 & C17 & C18 & C19 & C20 & C21 & $\mathrm{C} 22$ & C23 & C24 \\
\hline Maize & - & - & $\overline{-}$ & - & - & 9.0 & 23.7 & - & 67.3 & - & - & $\overline{-}$ & - & - & - & $\overline{-}$ & - & - & - & - & - \\
\hline Rice & - & - & - & - & - & - & 11.3 & - & 3.7 & 12.1 & 44.8 & 28.0 & - & - & - & - & - & - & - & - & - \\
\hline Beet & - & - & - & - & - & - & 2.9 & - & 85.3 & - & - & - & - & - & - & - & 7.8 & - & 4.1 & - & - \\
\hline Carrot & - & - & - & - & - & - & - & - & - & - & - & - & - & - & - & - & - & - & - & - & - \\
\hline Sweet Potato & 48.5 & 21.5 & - & - & 7.2 & 7.9 & - & - & - & - & - & - & 10.7 & - & 4.2 & - & - & - & - & - & - \\
\hline Tobacco & - & - & - & - & - & 21.9 & 29.2 & 21.1 & 27.8 & - & - & - & - & - & - & - & - & - & - & - & - \\
\hline Pea & - & 47.0 & 53.0 & - & - & - & - & - & - & - & - & - & - & - & - & - & - & - & - & - & - \\
\hline Salt Cress & - & 17.5 & 7.8 & 3.8 & - & - & - & - & - & - & - & - & - & 2.4 & 30.3 & 2.0 & 21.6 & & 14.6 & - & - \\
\hline Arabidopsis & - & 3.3 & 2.8 & 2.8 & - & 0.5 & 0.6 & - & 0.7 & - & - & - & - & - & 15.6 & & 24.7 & 0.4 & 48.8 & - & - \\
\hline Radish Aerial & - & 52.1 & 33.5 & 14.3 & - & - & - & - & - & - & - & - & - & - & - & - & - & - & - & - & - \\
\hline Radish Subterranean & - & 28.0 & 30.6 & 22.2 & - & - & - & - & - & - & - & - & - & - & 6.0 & - & 5.4 & - & 7.9 & - & - \\
\hline Daikon Aerial & - & 75.3 & 20.7 & 3.9 & - & - & - & - & - & - & - & - & - & - & - & - & - & - & - & - & - \\
\hline Daikon Subterranean & - & 59.1 & 24.1 & 10.3 & - & - & - & - & - & - & - & - & - & - & 5.6 & - & 0.9 & - & - & - & - \\
\hline Rapeseed & - & 1.9 & 5.4 & 6.5 & - & - & - & - & - & - & - & - & - & - & 2.6 & - & 32.9 & 1.8 & 47.4 & 0.7 & 0.8 \\
\hline Rutabaga Aerial & - & 32.6 & 17.2 & 16.8 & - & - & - & - & - & - & - & - & - & - & 2.6 & - & 17.9 & 0.2 & 12.7 & - & - \\
\hline Rutabaga Interface & - & 14.4 & 6.0 & 15.4 & - & - & - & - & - & - & - & - & - & - & 3.2 & - & 25.1 & 0.8 & 35.3 & - & - \\
\hline Rutabaga Subterranean & - & - & - & - & - & - & - & - & - & - & - & - & - & - & 3.2 & & 32.3 & 2.6 & 61.8 & - & - \\
\hline
\end{tabular}



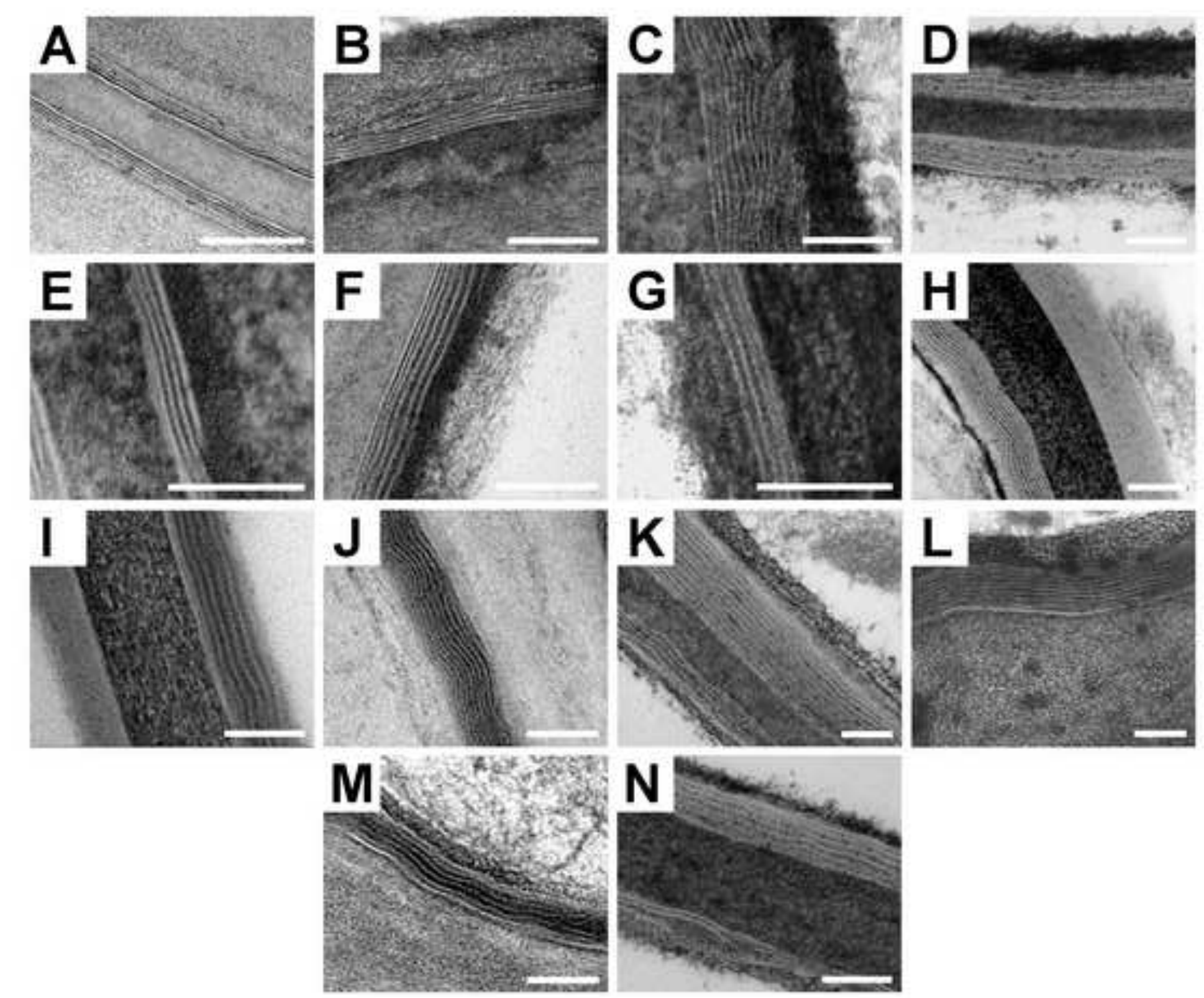


\section{A}
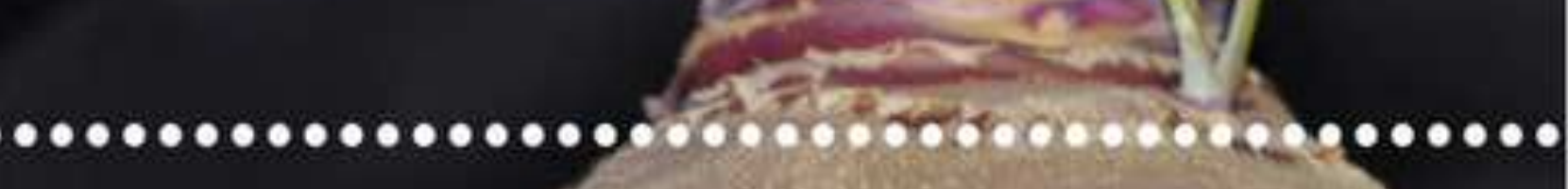

\section{Aerial}

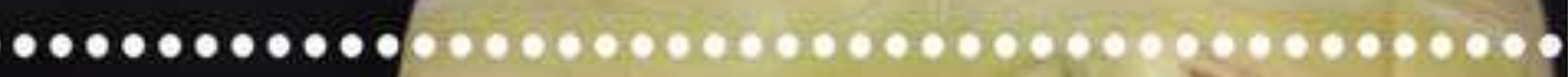

Subterranean
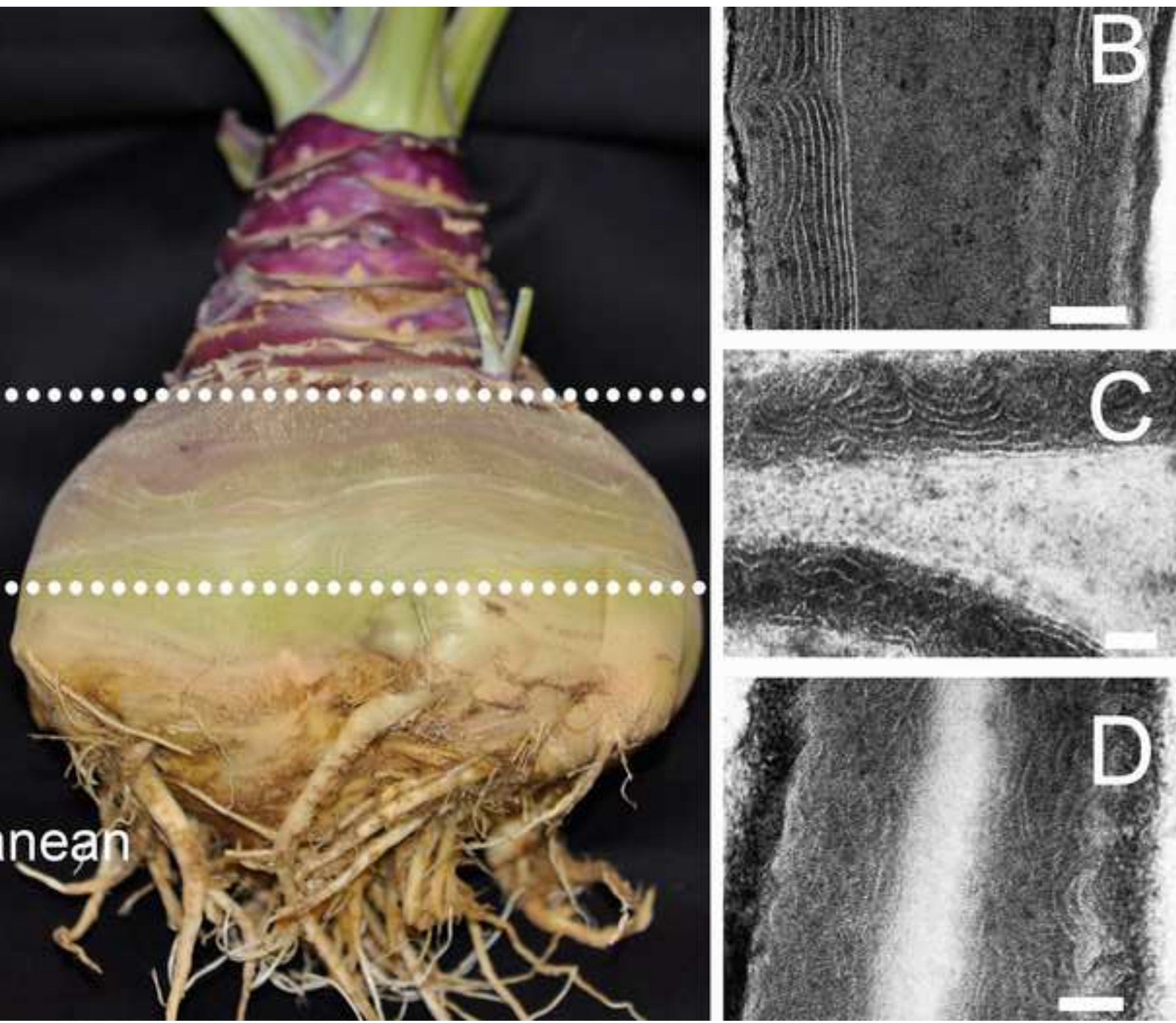

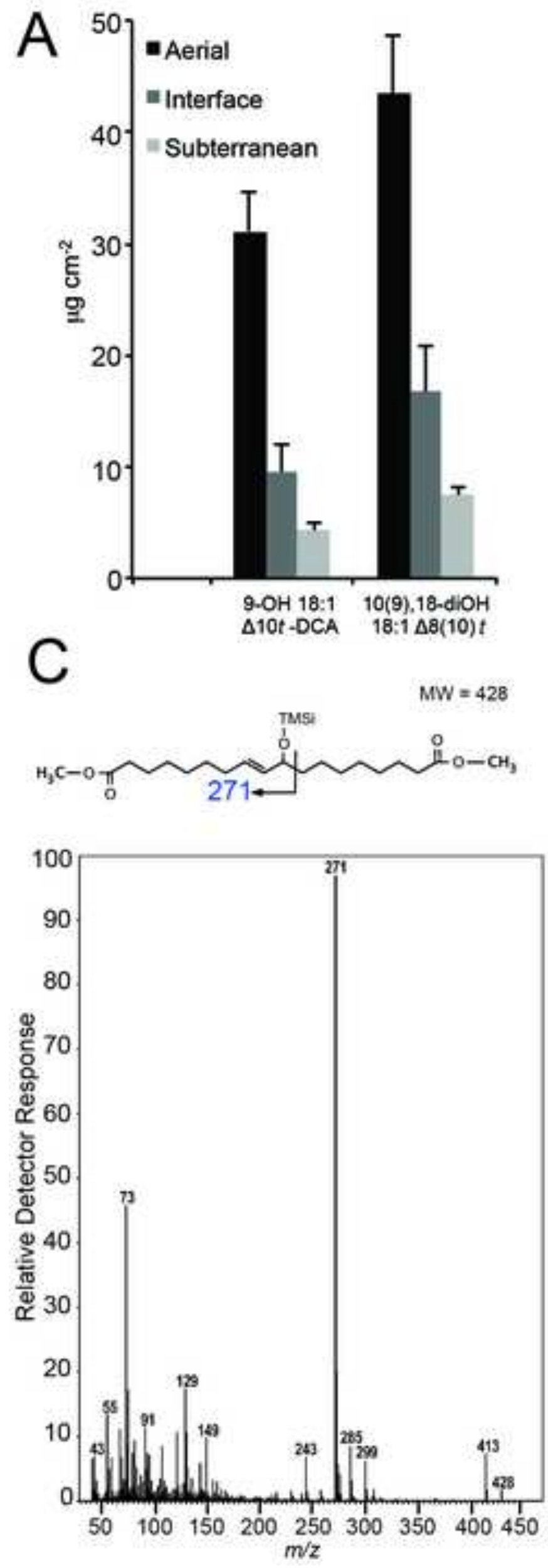
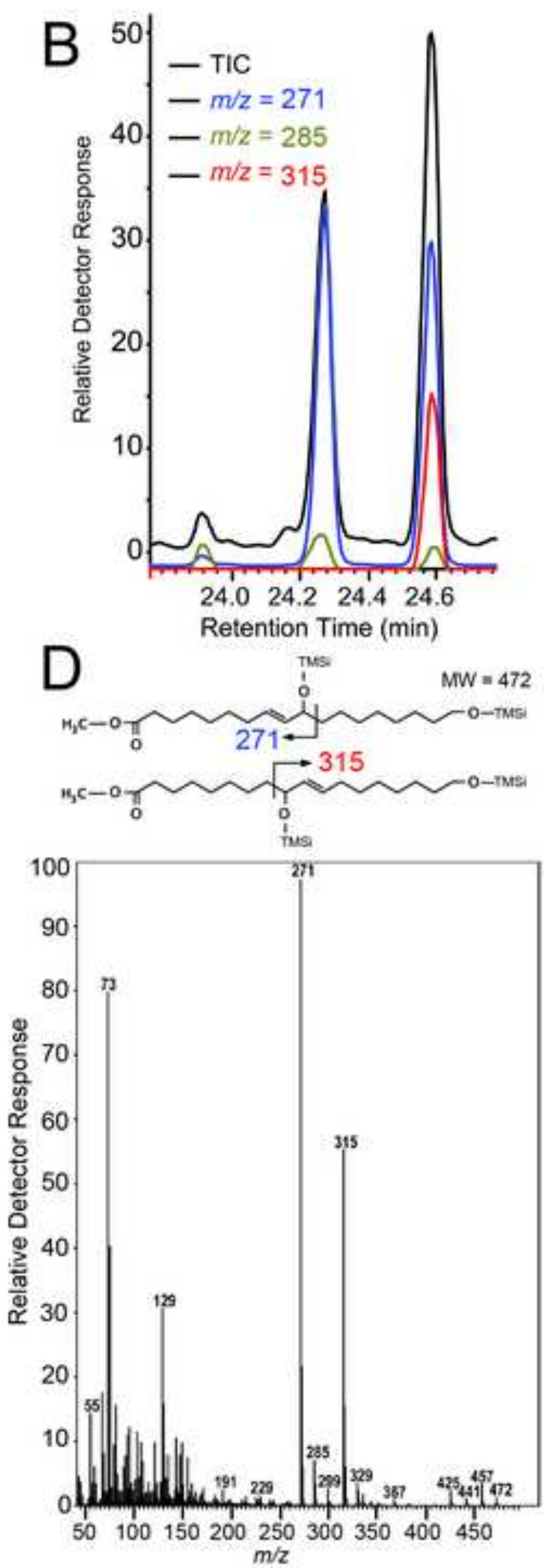


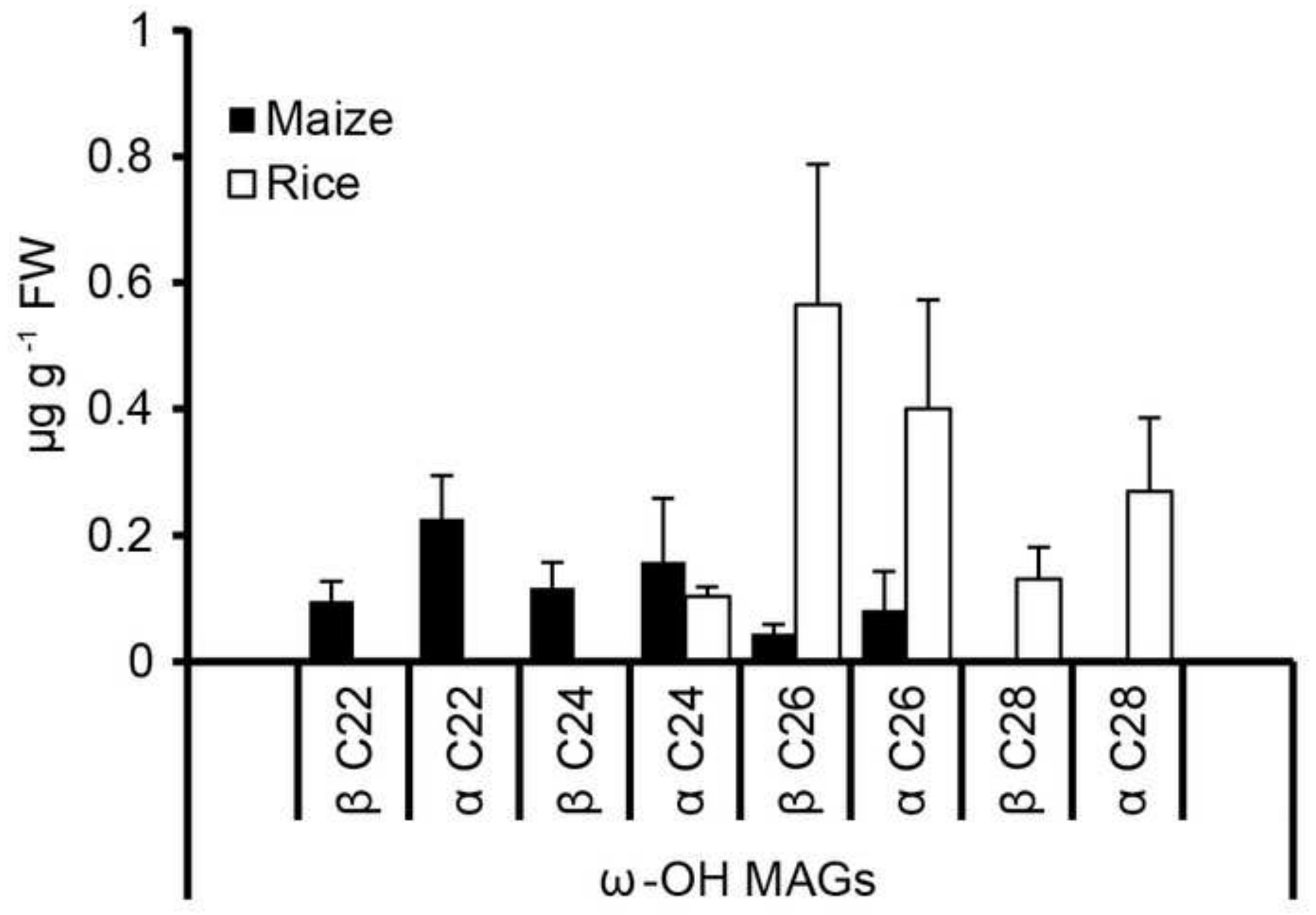



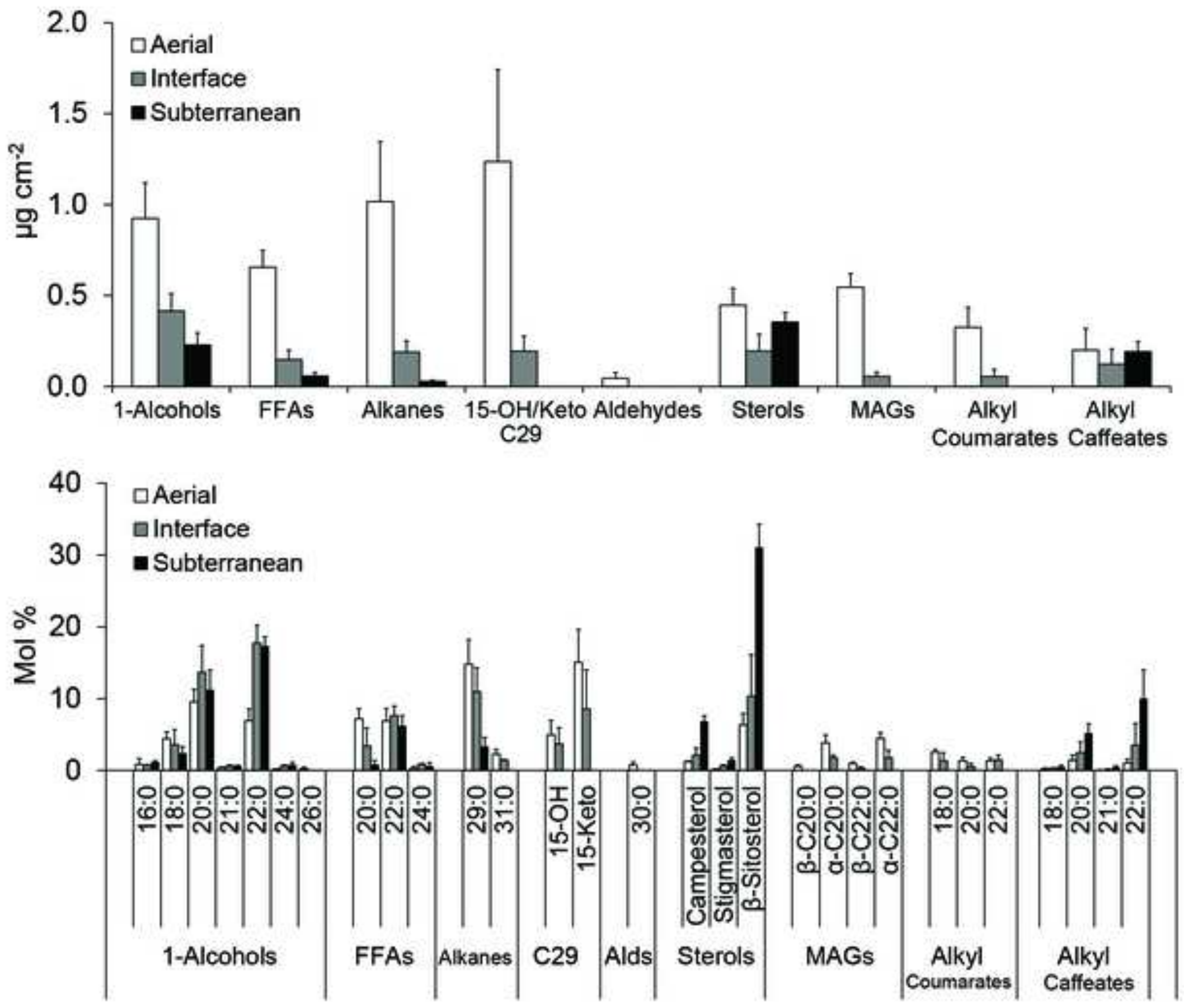


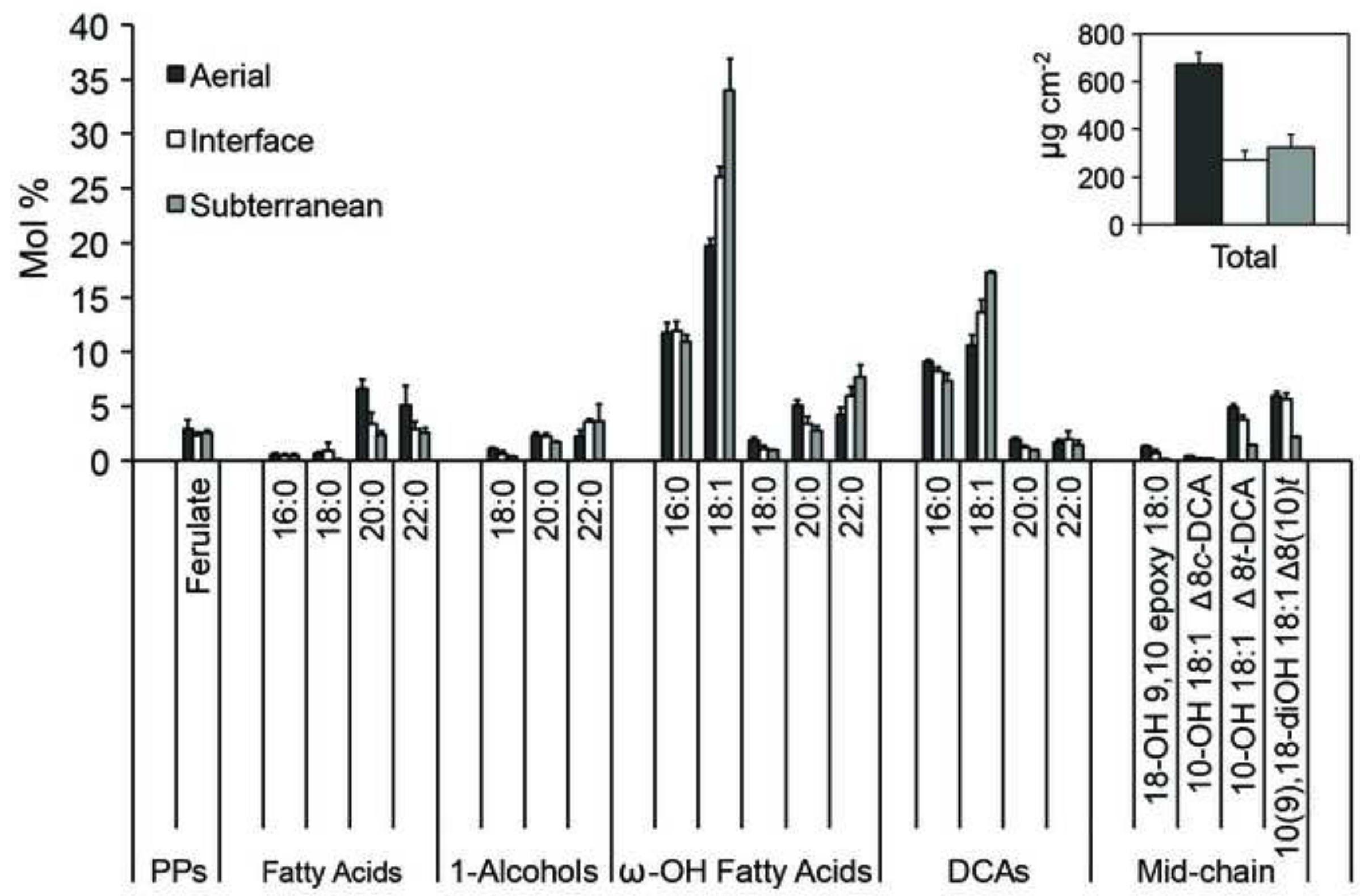




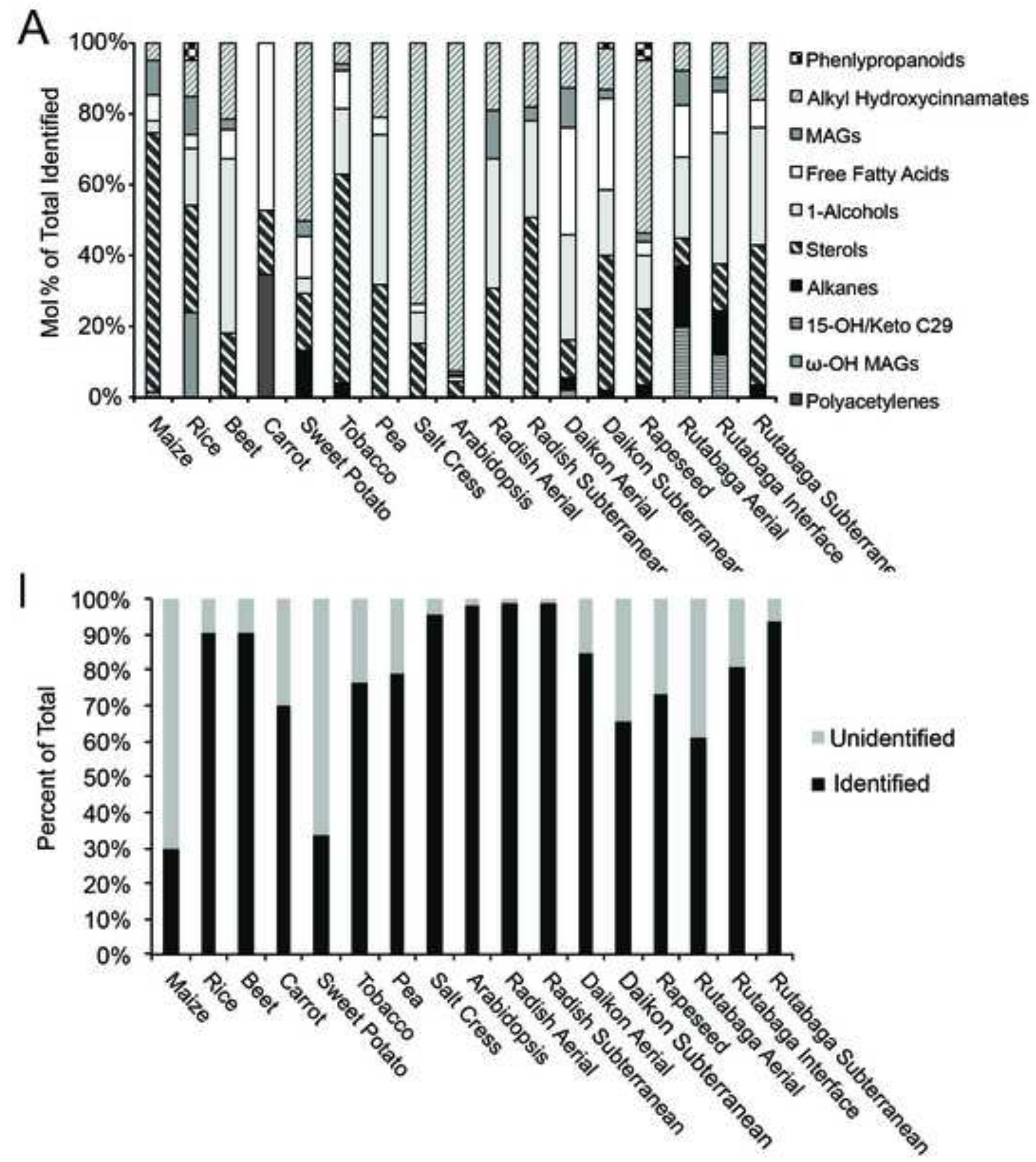




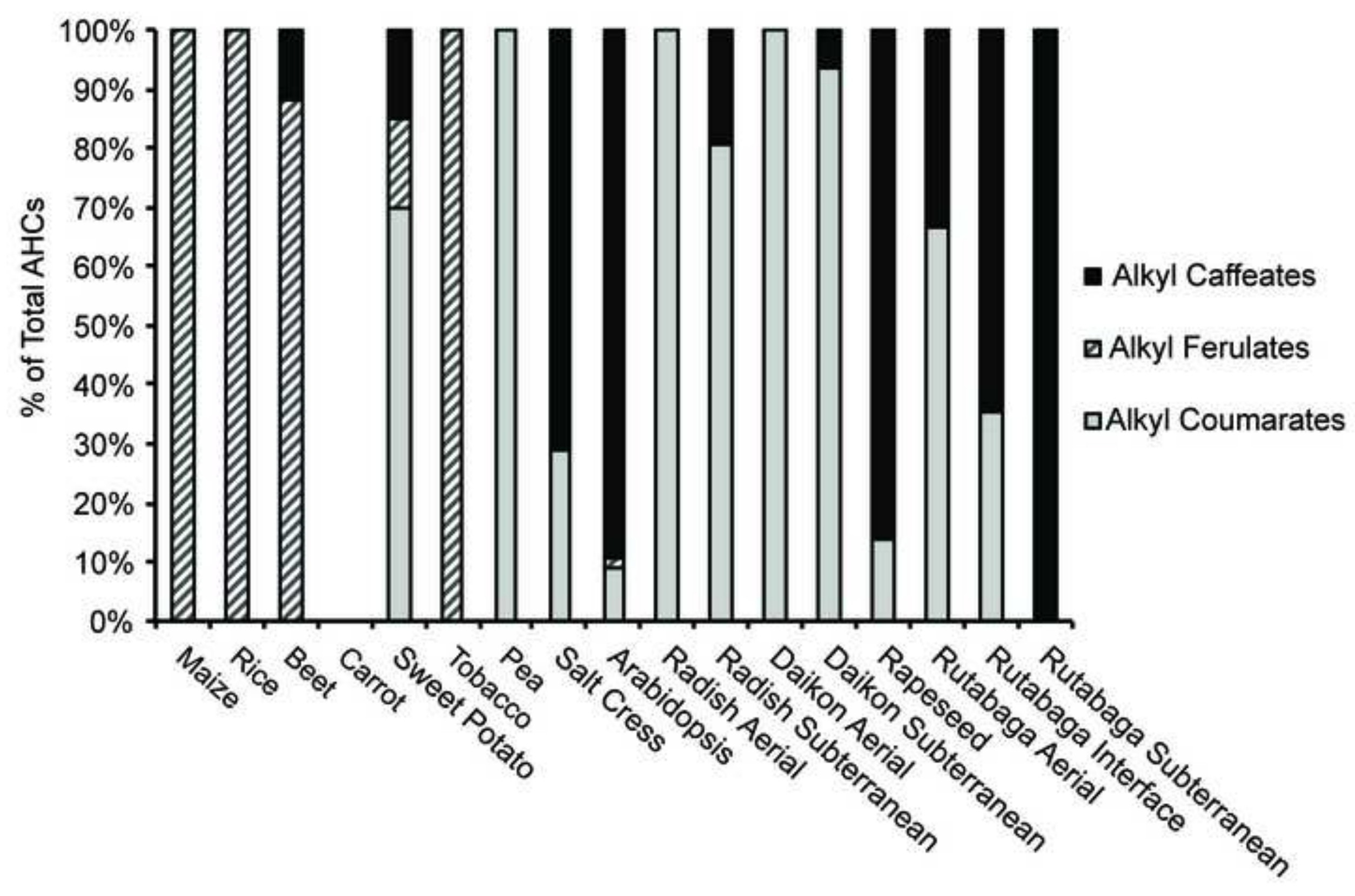




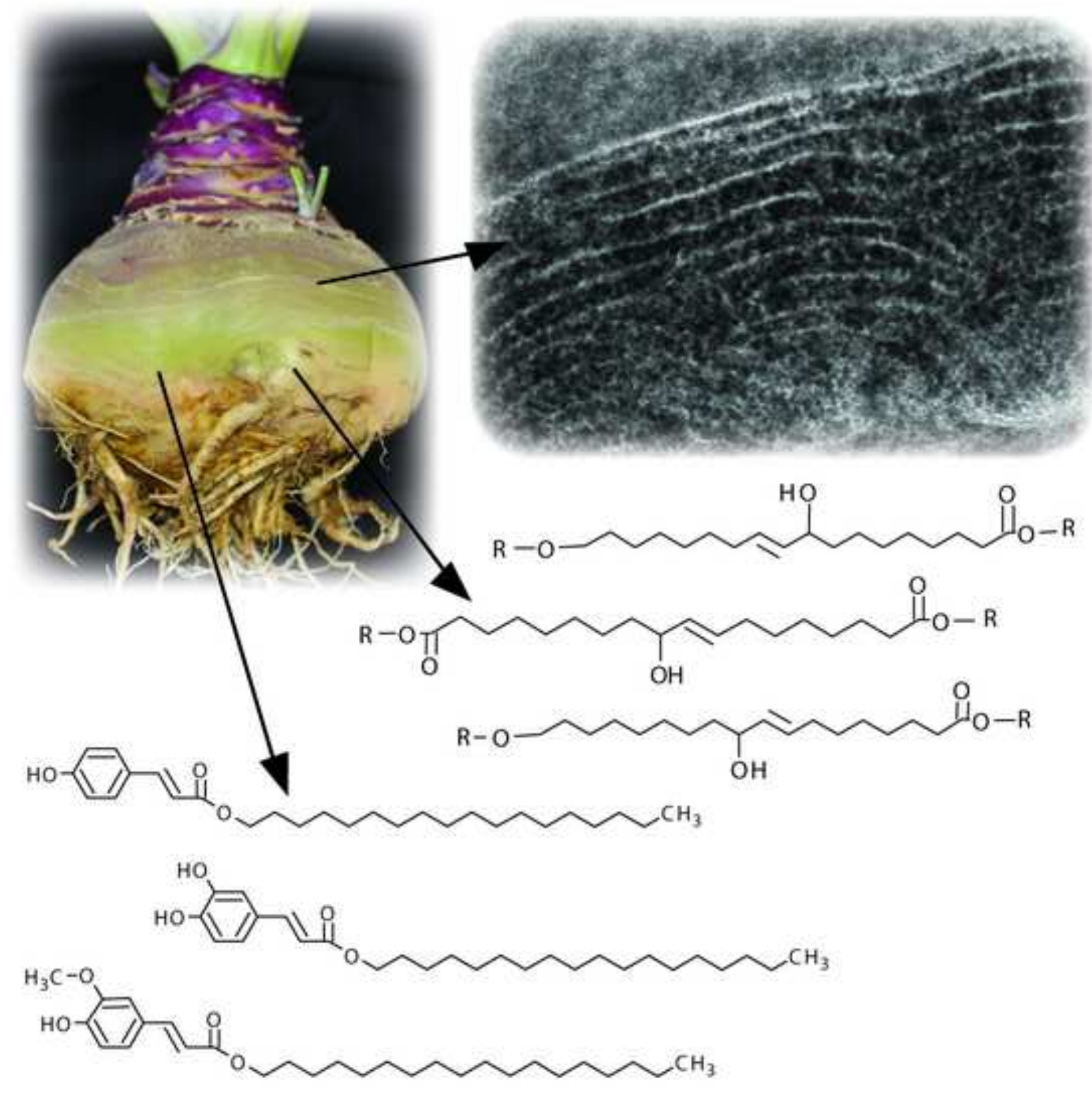

